Article

\title{
GIS and Optimisation: Potential Benefits for Emergency Facility Location in Humanitarian Logistics
}

\author{
Oscar Rodríguez-Espíndola ${ }^{1, *}$, Pavel Albores ${ }^{1, \dagger}$ and Christopher Brewster ${ }^{2,+}$ \\ 1 Aston Business School, Aston University, Birmingham B4 7ET, UK; p.albores@aston.ac.uk \\ 2 Data Science Group, Toegepast-Natuurwetenschappelijk Onderzoek (TNO), Soesterberg 3769 DE, \\ The Netherlands; christopher.brewster@tno.nl \\ * Correspondence: rodrigoe@aston.ac.uk; Tel.: +44-121-204-3262 \\ + These authors contributed equally to this work.
}

Academic Editor: Ruiliang Pu

Received: 30 December 2015; Accepted: 25 February 2016; Published: 29 March 2016

\begin{abstract}
Floods are one of the most dangerous and common disasters worldwide, and these disasters are closely linked to the geography of the affected area. As a result, several papers in the academic field of humanitarian logistics have incorporated the use of Geographical Information Systems (GIS) for disaster management. However, most of the contributions in the literature are using these systems for network analysis and display, with just a few papers exploiting the capabilities of GIS to improve planning and preparedness. To show the capabilities of GIS for disaster management, this paper uses raster GIS to analyse potential flooding scenarios and provide input to an optimisation model. The combination is applied to two real-world floods in Mexico to evaluate the value of incorporating GIS for disaster planning. The results provide evidence that including GIS analysis for a decision-making tool in disaster management can improve the outcome of disaster operations by reducing the number of facilities used at risk of flooding. Empirical results imply the importance of the integration of advanced remote sensing images and GIS for future systems in humanitarian logistics.
\end{abstract}

Keywords: humanitarian logistics; floods; geographical information systems; disaster management

\section{Introduction}

According to the United Nations Office for Disaster Risk Reduction, from 1992 to 20124.4 billion people were affected by disasters with almost 2 trillion USD in damages and 1.3 million people killed worldwide [1]. Approximately 2.6 billion people were affected by natural disasters from 1994 to 2003; more than the 1.6 billion affected in the previous decade [2]. Just in 2011, the total value of the damage caused by disasters globally was around US $\$ 366.1$ billion, the highest ever registered [3].

Different types of disaster require different types of response [4,5] given the varying features of each type of hazard. Among all disasters, floods are one of the most common [6,7] and destructive phenomenon world-wide [8,9]. Over 100 floods occur on average per year, and more than 150 occurred each year between 2007 and 2012 [1]. These disasters provide more time to react [10] because floods are more easily predicted and prevented compared to other disasters [11]. As a result, the use of systems for monitoring and analysis can improve preparedness and response.

Flood preparedness encompasses the readiness of a region to cope with a disaster based on the decisions and activities performed before the disaster occurs [12], whereas disaster response involves activities during the disaster to mitigate damage [13]. Adequate planning and preparedness can significantly affect the effectiveness of disaster response activities.

Features such as topography and weather predictions are relevant for floods. For example, hydrological analysis of regions and basins [14] enables the analyst to predict floods using return 
periods [15], to obtain probability distributions to forecast floods based on rainfall data [16], and to generate mapping tools to estimate potential water heights and damaged zones [17]. Mapping and assessing floods can improve the provision of timely and accurate support for activities such as evacuation, sheltering and distribution.

A common trend of decision-support tools for humanitarian logistics is incorporating the use of Operational Research techniques [13] to support disaster management. Geographical Information Systems (GIS) have been identified as relevant technologies to support decision-making [18]. However, articles in the field of humanitarian logistics are mostly including the use of GIS only for network analysis and data visualisation, e.g., $[19,20]$.

The purpose of this article is to show the importance of incorporating GIS along with optimisation for location and distribution decisions in cases of flood. Using a procedure developed by Martin [21] and supplemented by Rodríguez-Espíndola and Gaytán [22] by using map algebra, a macro in raster GIS (IDRISI ${ }^{\circledR}$ ) was used to provide input data for an optimisation model. Two case studies in Mexico are analysed to compare the use of the stand-alone optimisation model and the inclusion of geographical analysis for decision-making.

\section{Literature Review}

Whether focusing on shelters, emergency facilities or supply facilities, the geographical features of the area have been analysed using GIS.

Prathumchai and Samarakoon [23] addressed the selection of facilities for flood management based on the use of vector GIS. The method uses a flood map, road map, land elevation map and a map of facilities to determine the solution based on four criteria: the facility should be an existing school/college/hospital, it should not normally be in a floodable area, it should be within $1 \mathrm{~km}$ of a road, and it needs to be located at a high ground. Overlaying layers of these criteria, facilities remaining are discriminated using a cost surface representing the difficulty to access a shelter. Next, results are filtered by facility capacity. Finally, a calculation of the best way to go to determine the best evacuation path (least-cost path) can be performed by using the cost distance tool in $\operatorname{ArcGIS}^{\circledR}$.

El-Anwar et al. [24] merged a model developed by El-Anwar et al. [25] with GIS. The result was an automated system integrated into MAEViz software encompassing a three-part methodology: a safety model, analysis and visualization. MAEViz is used to estimate distances, output analysis, visualization, and as a ranking tool. Saadatseresht $e t$ al. [26] also proposed a three-step procedure: firstly, safe places for evacuation are selected through aerial/satellite image processing. Then, candidate facilities are chosen for each demand area considering the nearest facilities. Finally, optimum routes are determined through the solution of a bi-objective optimization model aiming to minimise the total distance travelled by the population and maximise the capacity use of shelters. Alçada-Almeida et al. [27] designed a p-median model seeking to minimise total travel distance, total risk in the primary path, fire risk at shelters, and total time required to transfer people from shelters to hospitals. The method uses SIGUrb to calculate the distance of each solution from its ideal solution. Coutinho-Rodrigueset al. [28] extended that paper considering backup evacuation paths and adding two objectives: minimisation of total risk of the evacuation paths and minimisation of the total number of shelters. Chanta and Sangsawang [29] uses GIS to discriminate facilities above certain height to reduce the chance of being flooded, and then the candidate facilities are introduced into the optimisation model to maximise coverage and minimise distance travelled.

The location of disaster recovery centres for FEMA in Florida was tackled by Dekle et al. [30]. The authors proposed the use of vector GIS software $\left(\mathrm{ArcView}^{\circledR}\right)$ to perform spatial analysis to determine potential locations for facilities. Each facility is weighted according to five factors (security, safety, accessibility, site requirements and equipment) and an uncapacitated location set covering problem is solved to minimise the total number of centres needed.

There are several contributions using GIS for the location of supply facilities. Tzeng et al. [31] provided a fuzzy dynamic model encompassing the distribution from suppliers to customers. 
The three-objective model aims to minimise total cost, total travel time, and maximise the minimal satisfaction during the planning period. Vector GIS (TransCAD ${ }^{\circledR}$ ) is used to identify the shortest routes and alternatives. Horner and Downs [19] proposed a general network flow modelling approach to identify accessible locations. The model minimises the assignment costs of servicing break of bulk points from warehouses and minimises assignment costs between facilities. A GIS (TransCAD ${ }^{\circledR}$ ) was used to manage the spatial data input and to visualize relief planning scenarios. Later on, Maliszewski and Horner [32] developed a model for facility construction aiming to maximise the total weighted distance from all potential targets to each facility and to minimise the total weighted distance of populations assigned to their closest facility. The authors include the use of vector GIS (ArcGIS ${ }^{\circledR}$ ) for network analysis, data processing and display of results considering both Euclidean and network distances. Widener and Horner [33] extended work by Teixeira and Antunes [34] by exploring the use of the hierarchical capacitated-median model with maximal travel distance constraints. GIS is used to identify accessible relief facilities and the model is aiming to minimise travel cost. Considering random failures on the roads, Salman and Yücel [35] designed a model aiming to maximise expected demand coverage using a scenario-based approach and prioritising areas expected to be more damaged. Vector GIS (ArcGIS ${ }^{\circledR}$ ) is used to determine the shortest path based on the road network.

Recently, GIS technology has been applied for more than only data analysis and visualisation. Barzinpour and Esmaeili [36] presented a two-echelon disaster supply chain for relief items and equipment. They consider the importance of the features of disaster by using the Risk Assessment tool for Diagnosis of Urban Areas against Seismic Disaster (RADIUS) to obtain the parameters for different earthquake scenarios. The formulation includes three objective functions aiming to maximise coverage, minimise location costs and minimising operational costs (transportation cost, holding cost and penalty costs for shortages). Extending that by considering coverage outside of the region, Esmaeili and Barzinpour [37] proposed the second objective function to minimise the sum of all costs and the third one to maximise coverage outside of the municipal area.

Providing a risk-based methodology, Zhao and Chen [38] used GIS to quantify severity and vulnerability, to map risk, and to support an optimisation model. The model aims to maximise coverage, minimise total weighted distance and minimise the maximum distance between a demand unit and the supply facility (as an equity measure). Ahmadi et al. [39] included real-time data on the actual transportation network condition. They proposed a static two-stage stochastic multi-commodity model with random travel time considerations with the goal of minimising a combination of travel time, penalty costs for unsatisfied demand, location cost, penalties for violation of the standard relief time and the expected total distribution time.

Exploring the location of emergency facilities, Rodríguez-Espíndola and Gaytán [22] developed a methodology for flood preparedness including a GIS analysis to discard floodable facilities and identify road failures. The model seeks to minimise total cost and total distance travelled considering priorities for the most affected areas.

The use of GIS for modelling humanitarian logistics has been increasing considerably in recent years. Nevertheless, the application of GIS has been limited in most of the articles to network analysis and visualization. Vector GIS has been used to determine road and Euclidian distances, along with routes. Similarly, it has been used to show the results from optimisation models to enable decision-makers to acquire a better understanding of the situation.

Recent articles demonstrate the possibility to provide further assistance for disaster management using GIS. The capabilities of these systems can provide useful information about potential disasters, mapping damage and monitoring the evolution of the situation. This article is showing the advantages of integrating GIS into optimisation-based decision support systems for disaster management. This article introduces an analysis of two case studies using the procedure described by Martin [21] and supplemented by Rodríguez-Espíndola and Gaytán [22]. A macro was created to input data to an optimisation model developed by Rodríguez-Espíndola et al. [40], and empirical tests were run in both case studies in Mexico. 


\section{Geographical Procedure}

GIS has been identified as a valuable tool for disaster management [18,41,42] because of its potential to perform analysis and display results graphically to understand the emergency situation easily [43]. The use of spatial data to create a representation of reality can be defined as a GIS model [44].

Among the different types of modelling available on GIS, cartographic modelling is the simulation of a spatial decision-making process through the sequential combination of techniques and operations [45]. This type of modelling differentiates itself from others because of the function-oriented structure [46]. In this structure each step accepts one or more layers as an input to create another layer as output, repeating until a decision is reached [45].

Cartographic modelling uses map algebra to integrate maps of individual characteristics (e.g., soil type, altitude, population density) to treat them as variables that can be combined or transformed through specific functions [46]. This type of modelling is highly appropriate to tackle analytical problems because of the potential to create countless tailor-made map-processing capabilities [47]. For instance, Prathumchai and Samarakoon [23] proposed a very interesting application of this method for shelter location/evaluation by combining different layers.

Cartographic modelling allows deciding which data is required, deep analysis of the system to define the problem, the inclusion of different sources and types of spatial data, a structured process, and easiness for scenario comparison.

Disasters have inherent features that can be modelled using the characteristics of the area (such as depth or physical distribution) to support decision-making. Raster-based models can be very useful for disaster management because satellite images and digital elevation models are relevant data sources [44].

GIS can incorporate geographical features into decision support systems to add to the advantages of mathematical models. That is the reason GIS-based models have been successfully integrated with logistic models before [43] as well as with disaster management models, e.g., [11,29]. Cartographic modelling is a technique that can be used to obtain a structured procedure able to incorporate the relevant geographical components of the region analysed to include them into the decision-making process.

The geographical procedure used in this paper is illustrated on Figure 1. It incorporates a combination of vector and raster geographical information systems. The vector GIS is used for data pre-processing and post-analysis, whereas the cartographic model is integrated in raster GIS. 


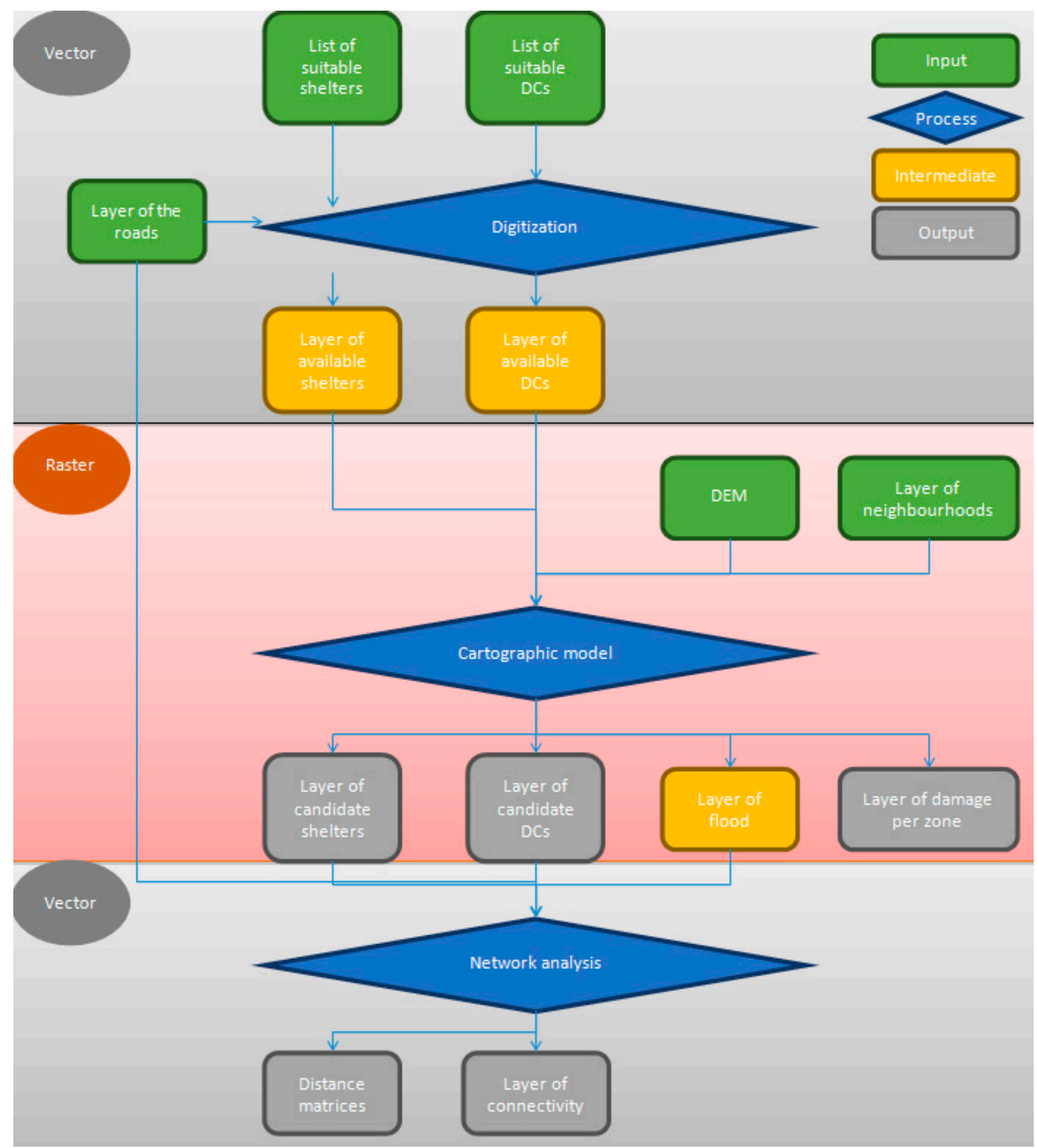

Figure 1. Geographical procedure.

\subsection{Identification of Suitable Facilities}

Emergency facilities play a vital role in the development of logistical operations for disaster management. Prior to the application of any procedure, it is important to determine appropriate facilities to serve as shelters and DCs.

\subsubsection{Shelter Standards}

Table 1 shows the minimum living requirements identified by Sphere_Project [48] and CENAPRED [49] from an international and Mexican perspective, respectively. 
Table 1. Living requirements for shelters.

\begin{tabular}{cccc}
\hline \multirow{2}{*}{ - } & Requirement & CENAPRED & Sphere Project \\
\hline \multirow{4}{*}{ Conditions } & Total space available per person & - & $45 \mathrm{~m}^{2}$ \\
& Minimum volume of air per person & $10.0 \mathrm{~m}^{3}$ & - \\
& Minimum distance between beds & $0.75 \mathrm{~m}$ & - \\
& Minimum covered floor area & $3.5 \mathrm{~m}^{2}$ & $3.5 \mathrm{~m}^{2}$ \\
\hline \multirow{2}{*}{$\begin{array}{c}\text { Personal } \\
\text { hygiene }\end{array}$} & Washbasin & One per 10 people & - \\
\cline { 2 - 4 } & Shower & One per 50 people (warm weather) & - \\
\hline \multirow{3}{*}{ Toilets } & one per 30 people (hot weather) & - \\
& Hygiene facilities & Separate sections for male and female & - \\
& Female & One per 25 woman & - \\
& Minimum distance between buildings & One toilet and one urinal per 35 males & $50 \mathrm{~m}$ \\
\hline
\end{tabular}

Source: Compiled by author with information from Sphere_Project [48] and CENAPRED [49].

Several criteria beyond cost, time or distance have been used in the literature to find suitable facilities. Accessibility, capacity, adaptability, zone danger and a large number of roads close by are amongst the most relevant, e.g., [23,50-52]. The selection should be performed considering these factors as well to ensure an adequate level of service for disaster victims.

\subsubsection{Standards for Distribution Centres}

There is no official regulation for DCs in cases of disaster. However, rule NOM-120-SSA1-1994 contains the requirements for general storage facilities in Mexico [53], which are summarised on Table 2.

Table 2. Minimum requirements for storage facilities in Mexico.

\begin{tabular}{lll}
\hline Section & Requirement \\
\hline Courtyard & - & Avoid the accumulation of unused equipment, garbage, herbs. \\
& - Have adequate drainage and lighting. \\
\hline Building & - & Adequate condition of the buildings to avoid contamination of the products. \\
Floors & - & Should be waterproof, with slope towards the drainage, and adequate to ease cleaning. \\
Walls & - & Washable and waterproof painting. \\
Ceilings & - & Avoid accumulation of dirt and condensation to prevent mould and germs. \\
Windows & - & With protection to avoid the entrance of dust, rain and animals. \\
Doors & - & With protection to avoid the entrance of dust, rain and animals. \\
Hygiene & - & Should have toilets and washbasins in the bathrooms, and washbasins for cooking areas. \\
Ventilation & - & Adequate means for ventilation should be ensured. \\
\hline
\end{tabular}

Source: SSA [53].

The requirements are used to list suitable facilities to be used as input in the process displayed in Figure 1, in order to create a layer to include as part of the cartographic model.

\subsection{Digitization}

The next step is to create layers in the GIS with georeferenced information using the list of facilities. This process is called digitization and it can be performed either on raster or vector software. Vector software was chosen because the metadata of the road network includes information about each street, allowing the user to locate each facility easily and efficiently.

The digitization can be performed by importing the layer of the road network into the software and then creating a new point layer overlapping with the road network. A layer of shelters and another one for distribution centres can be created for analysis. 


\subsection{Cartographic Model}

To perform scenario analysis, a cartographic model was implemented as a macro in IDRISI ${ }^{\circledR}$. The parameter used to vary scenarios relies on the expected water height, with the goal of creating flood maps. Flood maps have shown advancements in the literature e.g., [7,8,54-56]. This approach was preferred because of the deterministic nature of the model, considering the potential to create a set of relevant scenarios based on whether predictions, hydrological analysis or historical data, see [57-64]. The cartographic model was obtained from the work of Martin [21] complemented with map algebra proposed by Rodríguez-Espíndola and Gaytán [22]; all integrated into a macro in IDRISI ${ }^{\circledR}$. The reason for the selection of this particular model over other methods found in the literature was (a) the purpose of this work in seeking to show the potential advantages of incorporating a GIS analysis in the decision-making process; and (b) the ease and accuracy of the results obtained by Rodríguez-Espíndola and Gaytán [22].

\subsubsection{Data Pre-Processing}

As shown on Figure 1, to use the macro developed four layers are required:

- The layer of available DCs, obtained from authorities or elaborated by the analyst.

- The layer of available shelters, obtained from authorities or elaborated by the analyst.

- The DEM of the area under study, obtained from online sources or from authorities.

- The demand unit of the region (e.g., neighbourhoods) obtained from authorities.

The last step before using the macro is to determine the reference level. This step has to be performed only once for the region, being used for all experiments and it is associated to the altitude of the area under study. For the macro to be used, the region should be brought to a "base situation" extracting the altitude of the area. Because of the accuracy of images and uncertainty as to the real altitude, the user can perform scenario analysis with the DEM. The value of the altitude can be determined as the point where the area is affected by an increase of one extra unit. If a water body is nearby, the reference would be the point when the water body leaves its natural course, i.e., overflows.

\subsubsection{Macro on IDRISI ${ }^{\circledR}$}

Having all the layers and information ready, the analyst can apply the macro displayed in Figure 2.

The macro was created using the Macro Modeler module on IDRISI ${ }^{\circledR}$. The DEM is used as a foundation to create the flood map. The squares in red are modules, whereas the squares in purple are maps.

The altitude of the area is incorporated using an initial module, being the resulting image subtracted from the DEM by using an overlay module and producing the "Base image". The expected height of the flood is included at the bottom initial module and subtracted using another overlay to create the "Situation" layer. To classify areas in flooded and dry, every section with a value under 0 is assigned a class " 0 " and the rest is deemed as class " 1 " by using a reclass module. Martin [21] suggested the use of the group module to join adjacent flooded pixels separated by small areas which are probably flooded as well. After the correction described, the reclass module is employed again to obtain the "Flood Image". Having a representation of the potential flood, Rodríguez-Espíndola and Gaytán [22] suggested that map algebra could be used to evaluate the damage caused by the flood and get rid of floodable facilities. Therefore, an overlay module is used to "multiply" the demand areas times the flood image, getting as a result a value of 0 on every zone under water and the ID of the demand unit for the rest. The area module can be employed to obtain the percentage of the initial area of the demand unit as well as the dry area after the flood. The layers of facilities are multiplied times the flood image using overlay modules, and finally the area module is used to obtain a list of facilities on dry sections only.

This procedure can be applied as many times as desired by the decision maker to perform scenario analysis for relevant situations. 


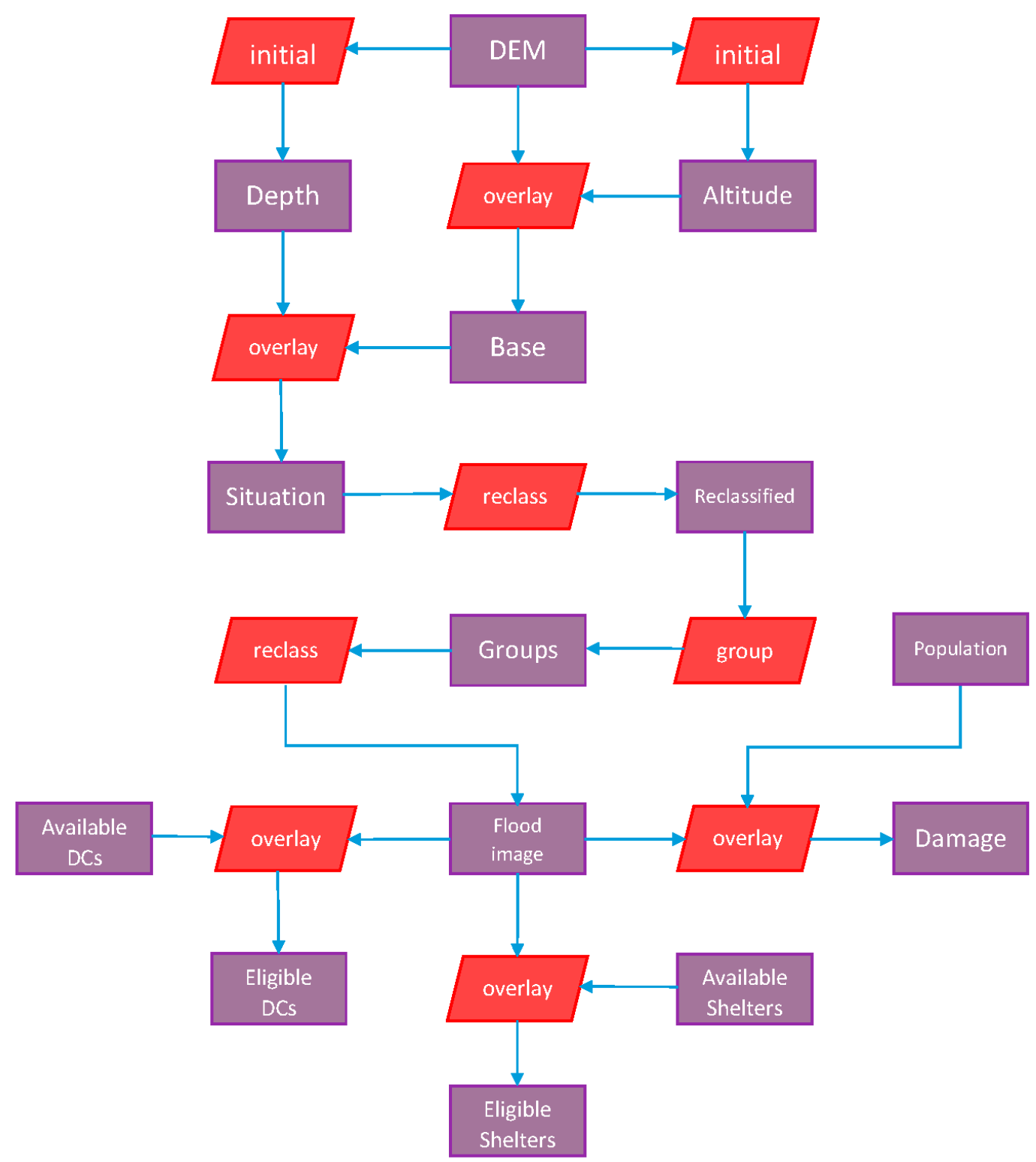

Figure 2. Cartographic model.

\subsection{Network Analysis}

The flood image can be superimposed with the road network to identify roads affected. This research is assuming a single collection point per demand unit for departure from affected areas to shelters, termed centroid. Having all the candidate facilities and demand points, the user can check the existence of roads available between any two points. However, the number of combinations can be monumental; therefore, the Floyd-Warshall algorithm is proposed as a time-saving option.

The Floyd-Warshall algorithm $[65,66]$ is one of the most widely used and effective algorithms to determine the shortest path between two points $[67,68]$. The algorithm is capable of finding the minimum distance between all pairs of nodes in a graph, even considering negative weights.

The algorithm compares the "current" direct distance with the distance obtained by visiting node $k$ in between nodes $i$ and $j$, and collecting the lowest value for the matrix. This way one matrix is computed for each node, hence, checking connectivity $k$ number of times. This algorithm is capable of finding a suitable route even if there was no value in the initial matrix, by verifying every path available. 
A common practice to determine the shortest distance between every pair of nodes is to compute Euclidian distances. Nevertheless, having GIS available, another level of detail can be attained by obtaining both road and Euclidian distances.

The results of the geographical procedure are a list of candidate facilities, a matrix of connectivity between facilities, a distance matrix, and a "percentage of damage" caused by the flood to the demand areas.

\section{Case Studies}

For this research, two cases were selected considering major floods in Mexico in different areas, and the description of each case can be found in Table 3. The flood depth of the situation in 2007 at Villahermosa [69] and the number of people sheltered [70,71] describe the magnitude of the event. Similarly, the height reached by the water in the disaster at Veracruz in 2010 [72] along with the number of people sheltered [73-75] is used to provide an overview of the situation. All the information gathered was used to analyse the system designed. The reasons for the selection of the cases in relation to the criteria aforementioned are:

- $\quad$ The events are two of the most notable floods lived in the country over the last 15 years, providing extreme conditions for the analysis.

- The characteristics among cases vary considerably in terms of damage, duration and number of people affected.

- The areas are relevant because of different reasons: the commercial importance of Veracruz [76] and the high level of vulnerability in Villahermosa [77].

Table 3. Case studies selected in Mexico.

\begin{tabular}{lll}
\hline Year & Location (City, State, Country) & Description \\
\hline \multirow{2}{*}{2007 Villahermosa, Tabasco, Mexico } & Flood depth: 4 m [69] & Start and end date: 29 October 2007-23 May 2008 \\
& Number of people sheltered: 99,000 [70,71] \\
\hline \multirow{2}{*}{2010 Veracruz, Veracruz, Mexico } & Flood depth: 1.5 m [72] \\
& Start and end date: 19 September 2010-19 October 2010 \\
& Number of people sheltered: 5140 [73-75] \\
\hline
\end{tabular}

\subsection{Veracruz, Mexico}

Located at the centre of the State of the same name, Veracruz has an altitude of $10 \mathrm{~m}$ above sea level. The city is within the hydrologic region Papaloapan with the basin R. Jamapa y Otros, experiencing an annual range of precipitation between 1100 and $1600 \mathrm{~mm}$ [78].

Figure $3[79,80]$ displays a representation of the terrain occupied by the city overlapped by the road network. The study is focused on the region Veracruz-Boca del Río. Boca del Río is a small section on the far south separated from Veracruz by one road. A total of 657,162 people lived in the region in 2010 [79]. 


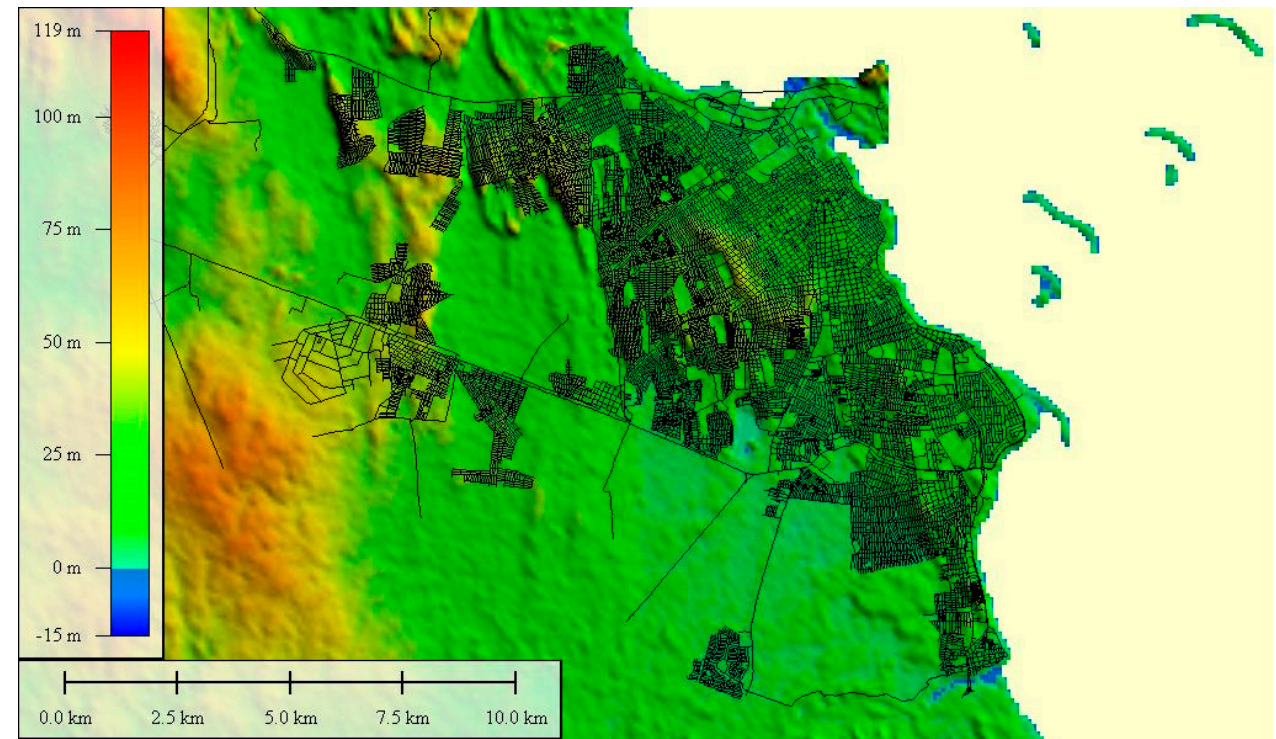

Figure 3. Region Veracruz-Boca del Río. Source: Compiled by author with information from USGS [80] and INEGI [79].

Hurricane Karl reached peak intensity on 17 September [81]. It caused 10-15 inch rainfall in half of Veracruz State, generating severe floods and several deaths in the State [81]. Because of the damage caused, authorities declared a state of emergency from 19 September 2010 to 19 October 2010.

\subsubsection{Layers Used for the Case of Veracruz}

The road network and demand areas were obtained from INEGI [79] on format shapefile. Every image obtained from INEGI was imported into IDRISI ${ }^{\circledR}$ from the NAD27 Lambert Conformal Conic projection. The road network is shown on Figure 4, including all of the streets in the area.

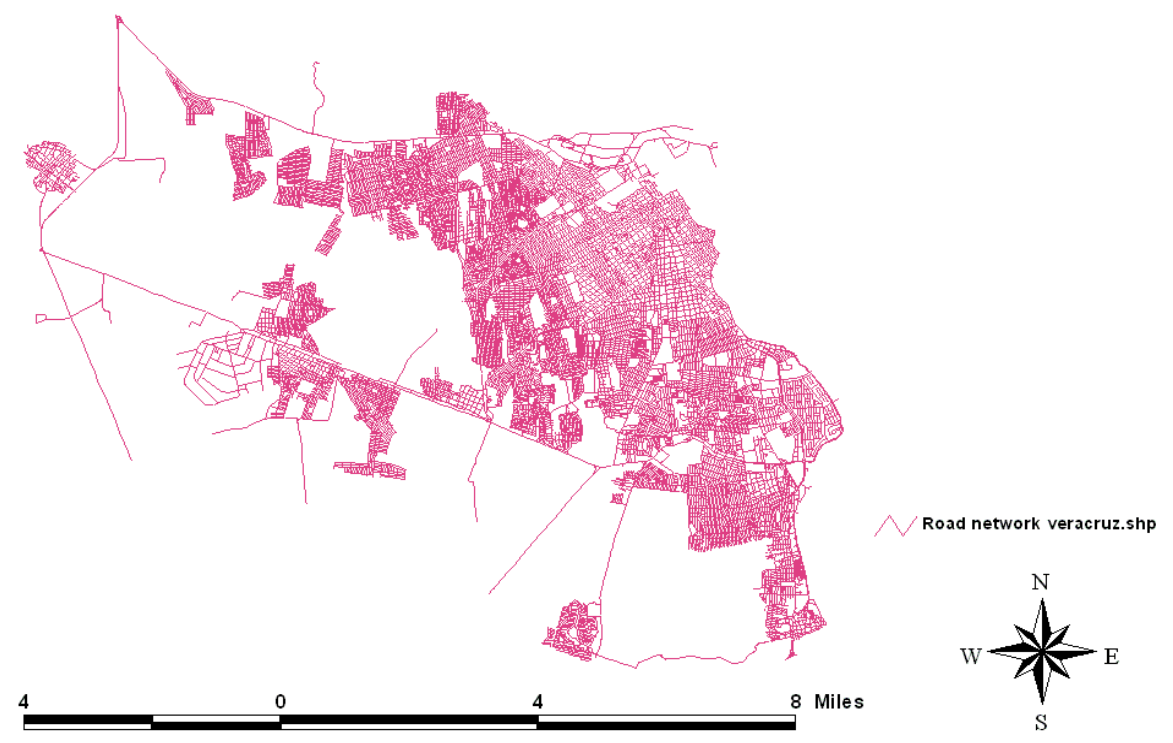

Figure 4. Road network of the region Veracruz-Boca del Río. Source: Compiled by author with information from INEGI [79].

The demand areas were based on AGEBs (from the Spanish Basic Geo-Statistical Areas). These units are considered by the Mexican government as an evolution of the neighbourhoods used 
previously. Each one of the AGEBs contains a database with the number of inhabitants there along with an identifier. The 315 of these units existent in the region under study can be seen in Figure 5.

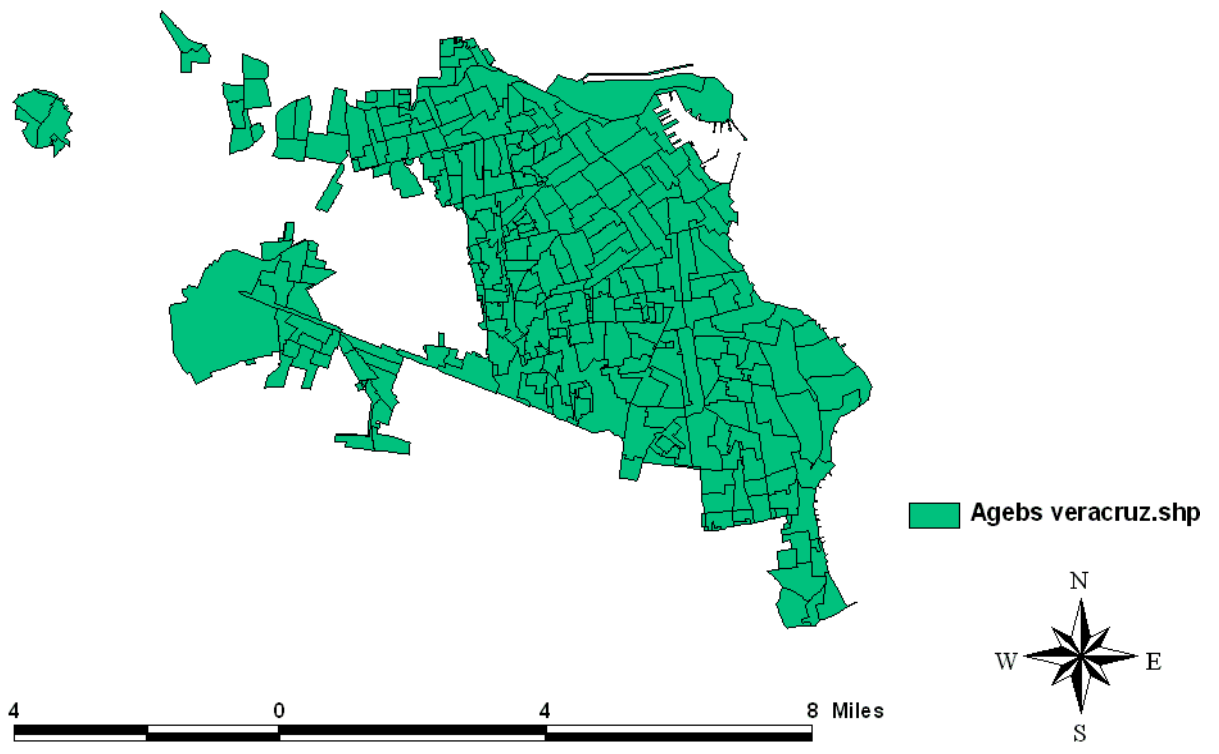

Figure 5. AGEBs of the region Veracruz-Boca del Río. Source: Compiled by author with information from INEGI [79].

Because of the importance of the DEM for the cartographic model, three DEMs of the area (two from INEGI [82] and one from USGS [80]) were acquired. One of the images from INEGI was discarded because it was based on a scale of 1:250,000, considered not accurate enough. The remaining image from INEGI had a scale of 1:50,000 and it was tested against the layer from USGS. In terms of reliability, the image from USGS showed to approximate reality better when comparing the measurements of each point with data from the real area obtained using Google Earth ${ }^{\circledR}$. Moreover, the image from USGS showed more sensibility to variations of altitude below $1 \mathrm{~m}$. Therefore, Figure 6 shows the DEM from USGS selected for the analysis.

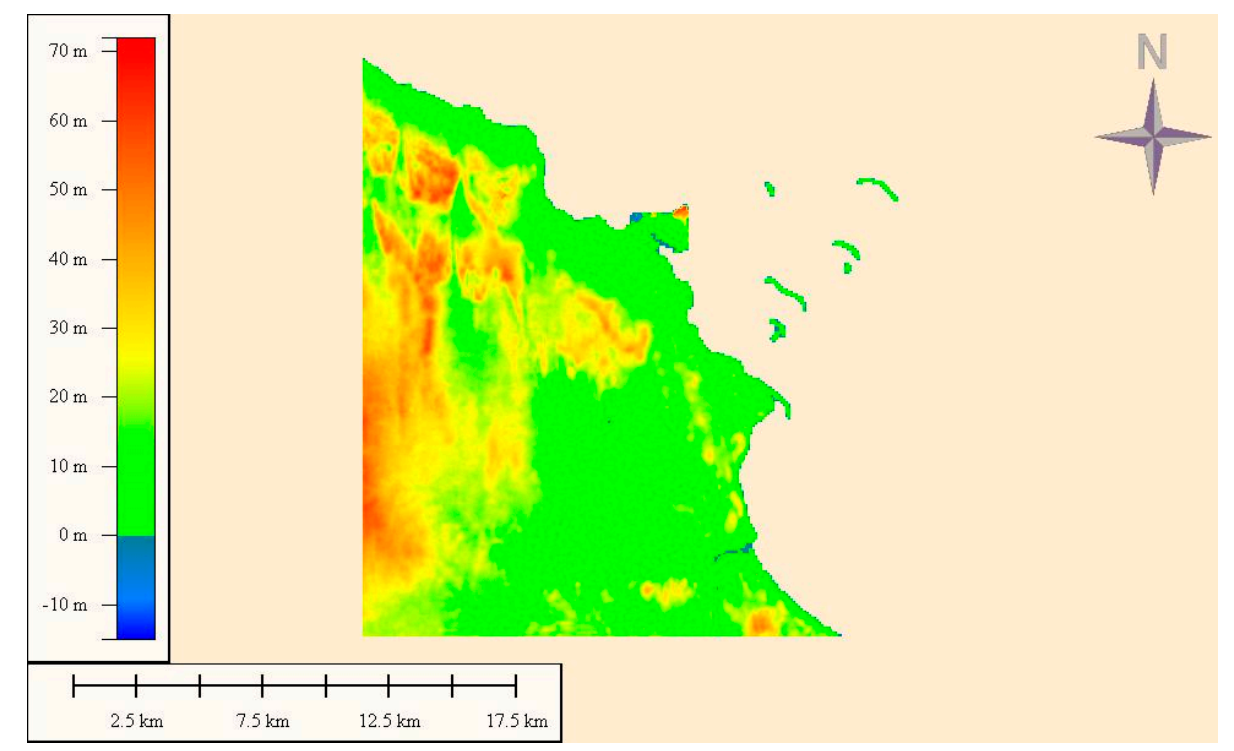

Figure 6. Digital elevation model of the region Veracruz-Boca del Río. Source: Compiled by author with information from USGS [80]. 
Information about potential shelters available in the region was provided by SEGOB [83]. The shelter catalogue contained 589 facilities within the municipality. Considering schools along with facilities already identified by the agencies in the city, a total of 44 suitable facilities were found. The six facilities already identified by authorities were provided by SSV [84], SEDENA [74] and PCV [85]. Similarly, facilities identified by authorities to serve by DCs were provided by SEDENA [86], DICONSA [87], PCV [88]; whereas three facilities were identified according to the guidelines of SEDENA [89], for a total of ten available DCs.

Using the process for digitization, a layer of shelters and another of distribution centres were obtained. An overlap of both layers over the road network can be seen in Figure 7.

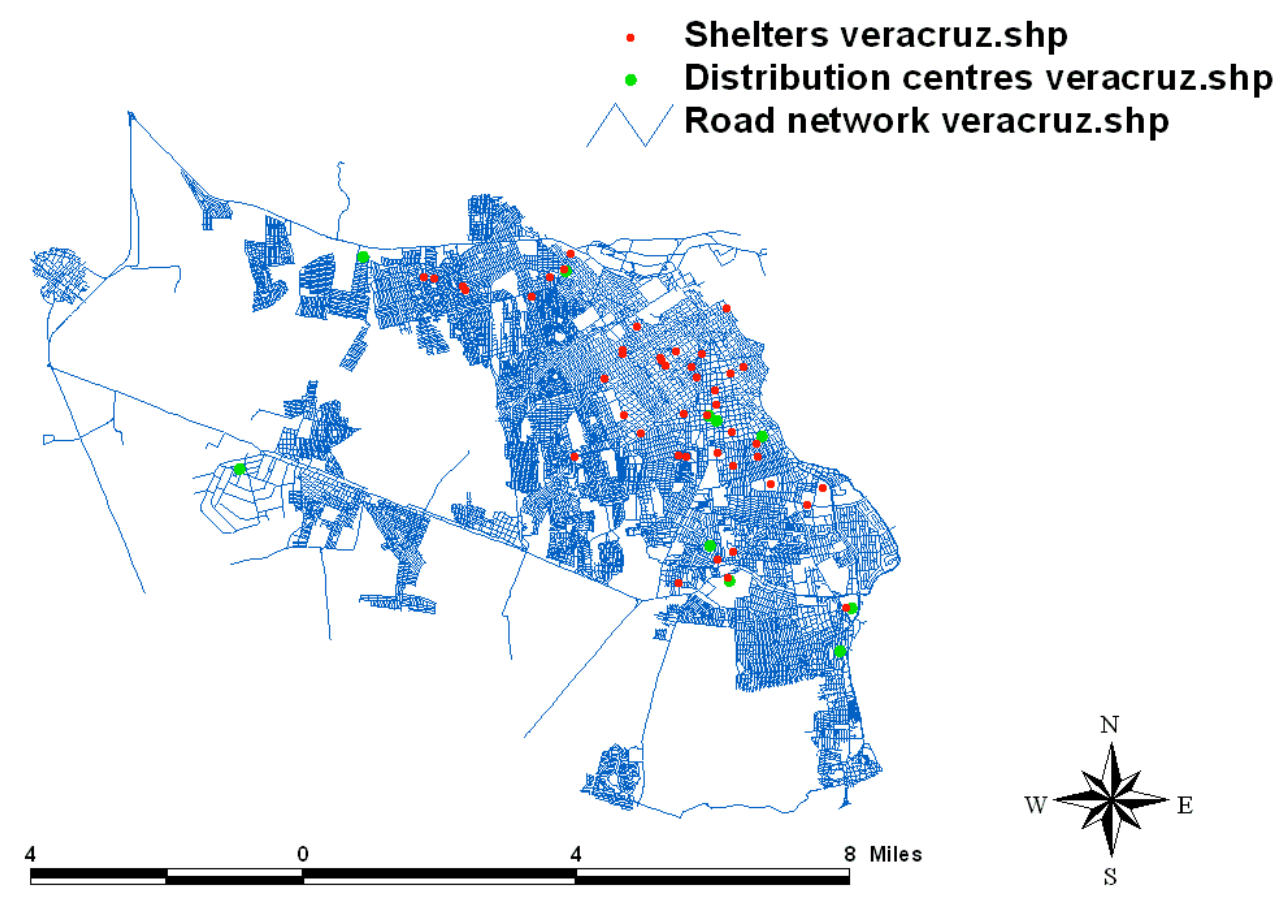

Figure 7. Location of the facilities available in the road network of the Veracruz-Boca del Río region.

\subsubsection{Application of the Cartographic Model}

According to official information, the city and regions surrounding it are supposed to be $10 \mathrm{~m}$ above sea level [78]. The importance of the baseline, however, drove us to perform a manual analysis ranging from 0 to $10 \mathrm{~m}$ to have reliable results. The baseline was determined at $6.5 \mathrm{~m}$. At this height, there is a significant change in the area when adding $0.5 \mathrm{~m}$, as it is supposed to happen when there is a flood. At lower values, the variations were minimal.

The flood in Veracruz is believed to have reached $1.5 \mathrm{~m}$ of water level [72], which was used as a representation of the real conditions. Also, a scenario of a flood of $0.5 \mathrm{~m}$ and another situation with a water level reaching $2.5 \mathrm{~m}$ were set for comparison. Applying the cartographic model described, the results of the three scenarios are shown in Figure 8. 


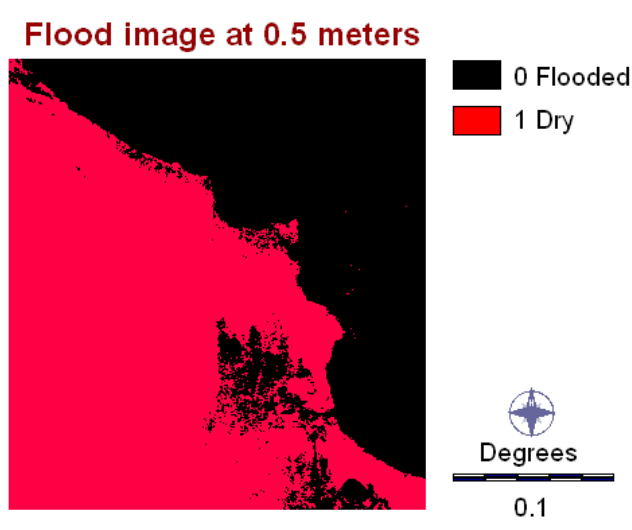

Flood image at 1.5 meters

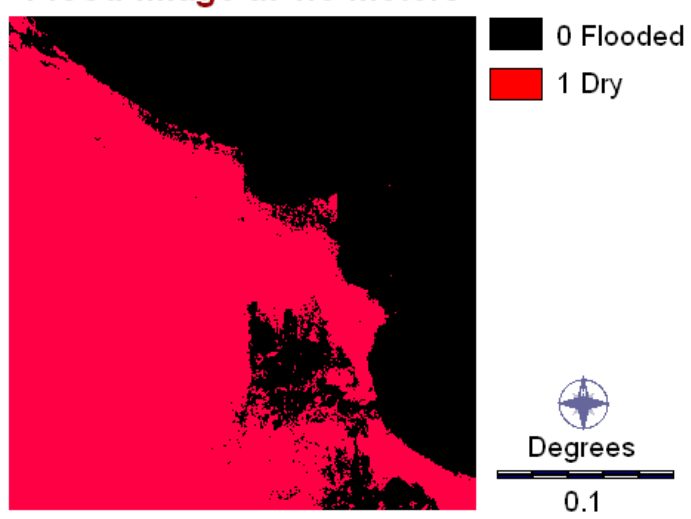

Flood image at 2.5 meters

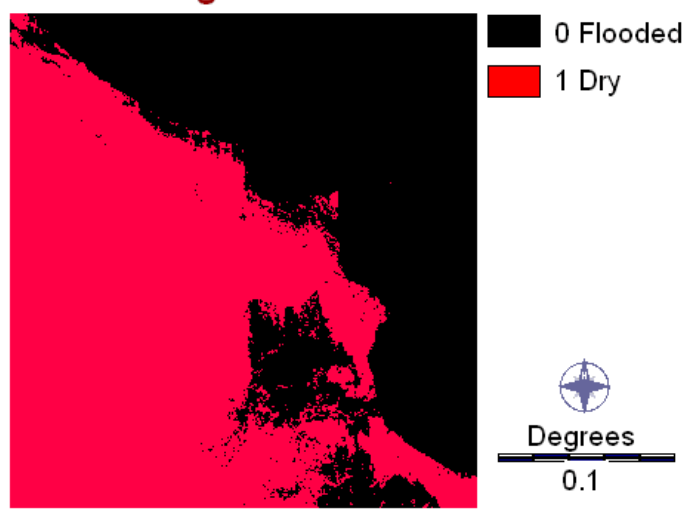

Figure 8. Floods of $0.5 \mathrm{~m}, 1.5 \mathrm{~m}$ and $2.5 \mathrm{~m}$ at Veracruz.

\subsubsection{Results of the GIS Procedure Applied to Veracruz}

In terms of damage to shelters and DCs, Figure 9 shows the candidate facilities.

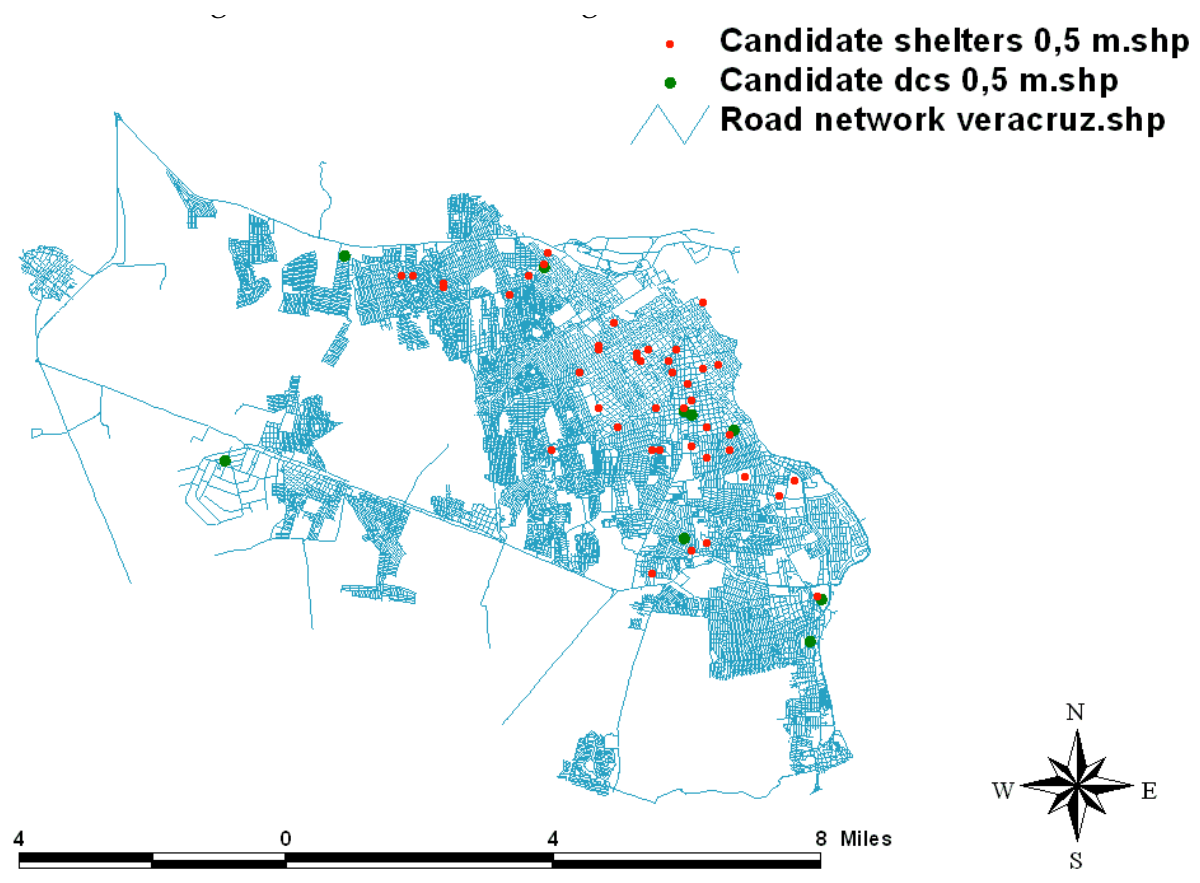

Figure 9. Cont. 

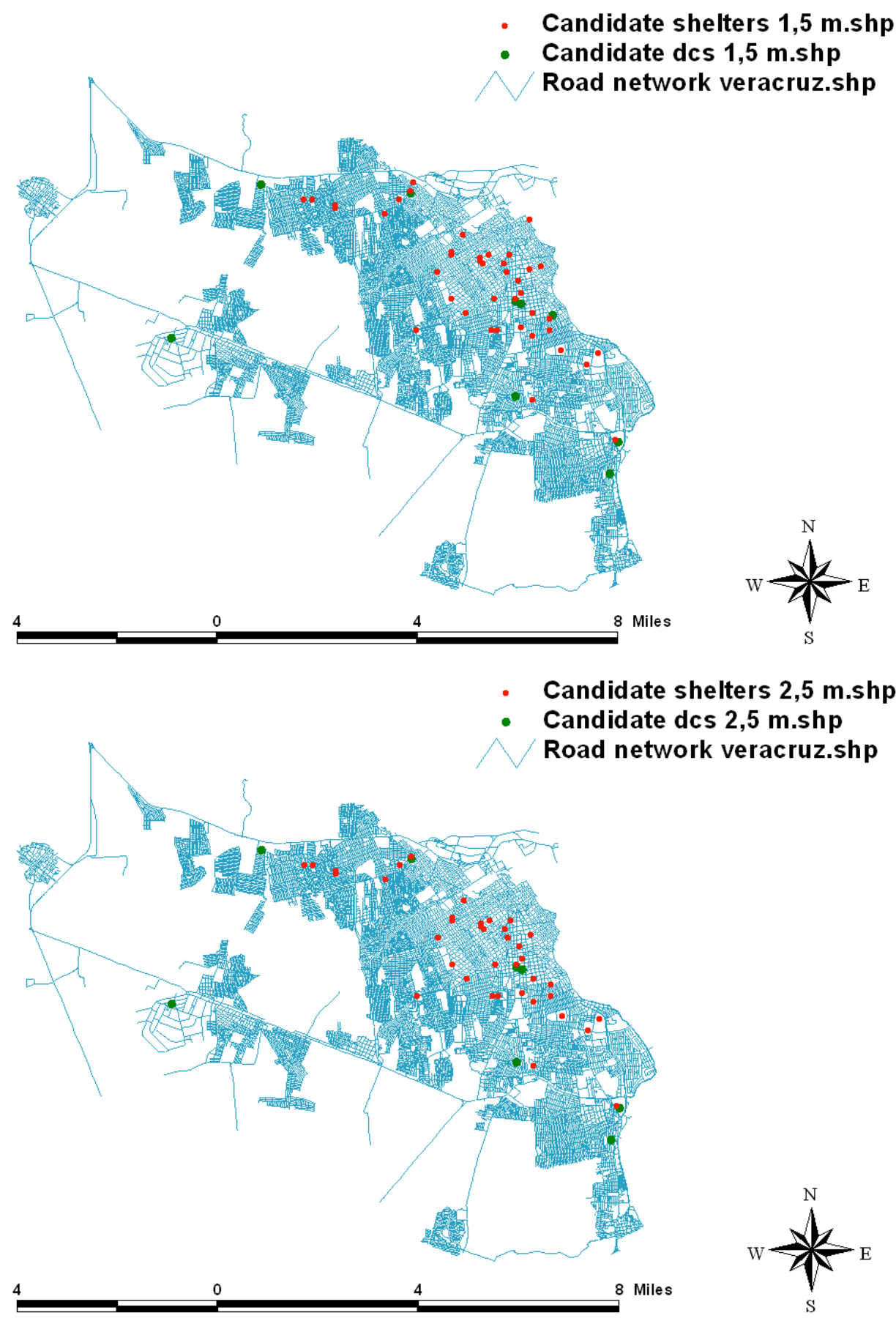

Figure 9. Surviving facilities for floods of $0.5 \mathrm{~m}, 1.5 \mathrm{~m}$ and $2.5 \mathrm{~m}$ at Veracruz.

There were a total of 43 surviving shelters and nine DCs at a depth of $0.5 \mathrm{~m} ; 41$ shelters and nine DCs available with a water level of $1.5 \mathrm{~m}$, and 38 shelters and eight DCs remaining for a situation of $2.5 \mathrm{~m}$ of water. Overall, the impact of the flood on the facilities was low.

Damage was estimated as follows: Damage $=\frac{A_{i}-A_{f}}{A_{i}} \times 100 \%$; being $A_{i}$ the total dry area before the flood and $A_{f}$ the final dry area after the flood. The flood of $0.5 \mathrm{~m}$ affected a nearly $21.6 \%$ of the total area, whereas the flood of $1.5 \mathrm{~m}$ and $2.5 \mathrm{~m}$ damaged around $25.4 \%$ and $32.7 \%$ of the region, respectively. Table 4 shows the number of AGEBs affected per level of damage in the scenarios considered, ranging from areas not affected to completely flooded AGEBS. 
Table 4. Number of AGEBs affected per percentage of damage.

\begin{tabular}{cccc}
\hline Percentage of Damage & $\mathbf{0 . 5} \mathbf{~}$ & $\mathbf{1 . 5} \mathbf{~}$ & $\mathbf{2 . 5} \mathbf{~}$ \\
\hline Not affected & 247 & 235 & 212 \\
$1<\mathrm{x}<10$ & 22 & 21 & 28 \\
$10<\mathrm{x}<20$ & 13 & 11 & 11 \\
$20<\mathrm{x}<30$ & 8 & 7 & 9 \\
$30<\mathrm{x}<40$ & 6 & 7 & 8 \\
$40<\mathrm{x}<50$ & 4 & 6 & 5 \\
$50<\mathrm{x}<60$ & 1 & 6 & 5 \\
$60<\mathrm{x}<70$ & 2 & 7 & 8 \\
$70<\mathrm{x}<80$ & 3 & 1 & 9 \\
$80<\mathrm{x}<90$ & 1 & 4 & 5 \\
$90<\mathrm{x}$ & 8 & 10 & 15 \\
\hline
\end{tabular}

Using the flood map, the road network, and the Floyd-Warshall algorithm; the connectivity between facilities was obtained. The tables contain the value of 1 if there is at least one road available between each pair of facilities and 0 otherwise. Air transportation was considered available between all facilities.

\subsection{Villahermosa, Tabasco}

Figure 10 shows an caption of the city of Villahermosa [90], county seat of the Municipality of Centro and the capital of the state of Tabasco, city with an average altitude of $10 \mathrm{~m}$ above sea level.

With a total population of 474,507 people in the last census [79], Villahermosa is the only Energy City in Latin America [91]. The relevance of the city is because of its significant gas and oil activity, with nearly $90 \%$ of natural gas produced in the country within a $200 \mathrm{~km}$ radius. The city is an economical axis for the region and a cornerstone of the oil and gas industry in the country.

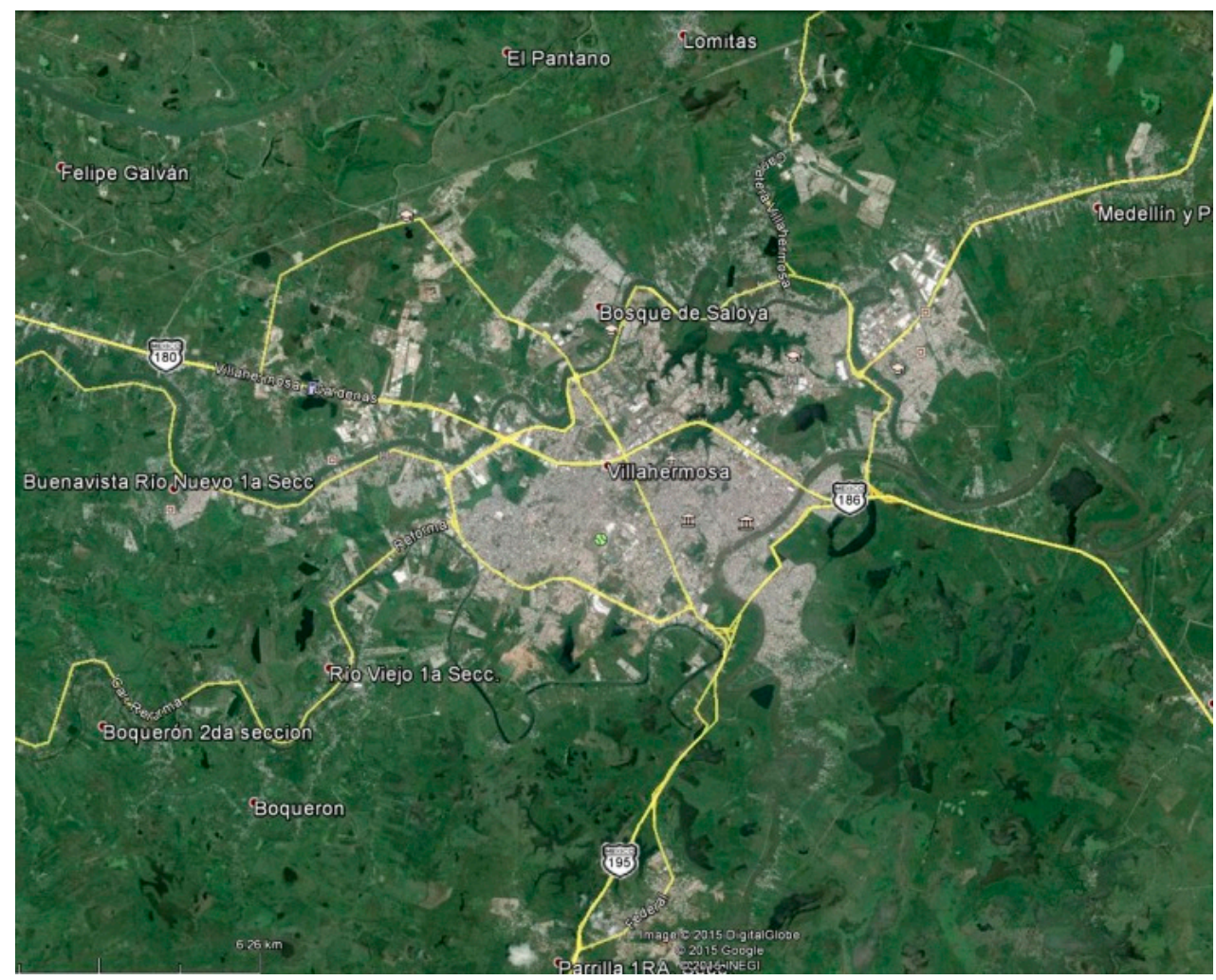

Figure 10. Villahermosa, Tabasco. Source: Google_Earth [90]. 
The geographical location of the city deserves considerable attention. The city is in the hydrological region Grijalva-Usumacinta, inside the delta created by three rivers: Grijalva, Usumacinta and Carrizales. Grijalva is the second most abundant river in the country and, in combination with Usumacinta river, the total unloading produced is around 125,000 million $\mathrm{m}^{3}$; the most significant system in North and Central America and the seventh globally [91]. Also, Villahermosa borders with the water body "Laguna de los Espejos" and it is close to "Las Peñitas" dam system, making the city a very prone area to flooding [92].

The region of Villahermosa has been commonly affected by floods with considerable economic damage in 1975, 1990 [69], 1999, 2007 and 2008 [92], as well as in 2009 [93].

This case is based on a riverine flood. The cold front number 4 caused extraordinary rainfall of nearly twice the historical average [94]. There was over $400 \mathrm{~mm}$ of rainfall in $24 \mathrm{~h}$ and nearly $1000 \mathrm{~mm}$ over three days [69].

The rainfall combined with the opening of floodgates of the "Peñitas" dam created a catastrophic situation with nearly $80 \%$ of the state covered by water. Water heights of four meters and more than one million people affected were the result of this catastrophic event [69]. Villahermosa was significantly affected, with around $90 \%$ of the area covered by water [95]. Also, this flood represented damage estimated in 31,800 million pesos (over 3100 million dollars) in the state of Tabasco alone; around $29.3 \%$ of the GDP of the State [94].

\subsubsection{Layers Used for the Case of Villahermosa}

The road network used was obtained from INEGI [79] and it is shown on Figure 11.

Figure 12 displays the 147 AGEBs of the city obtained also from INEGI [79].

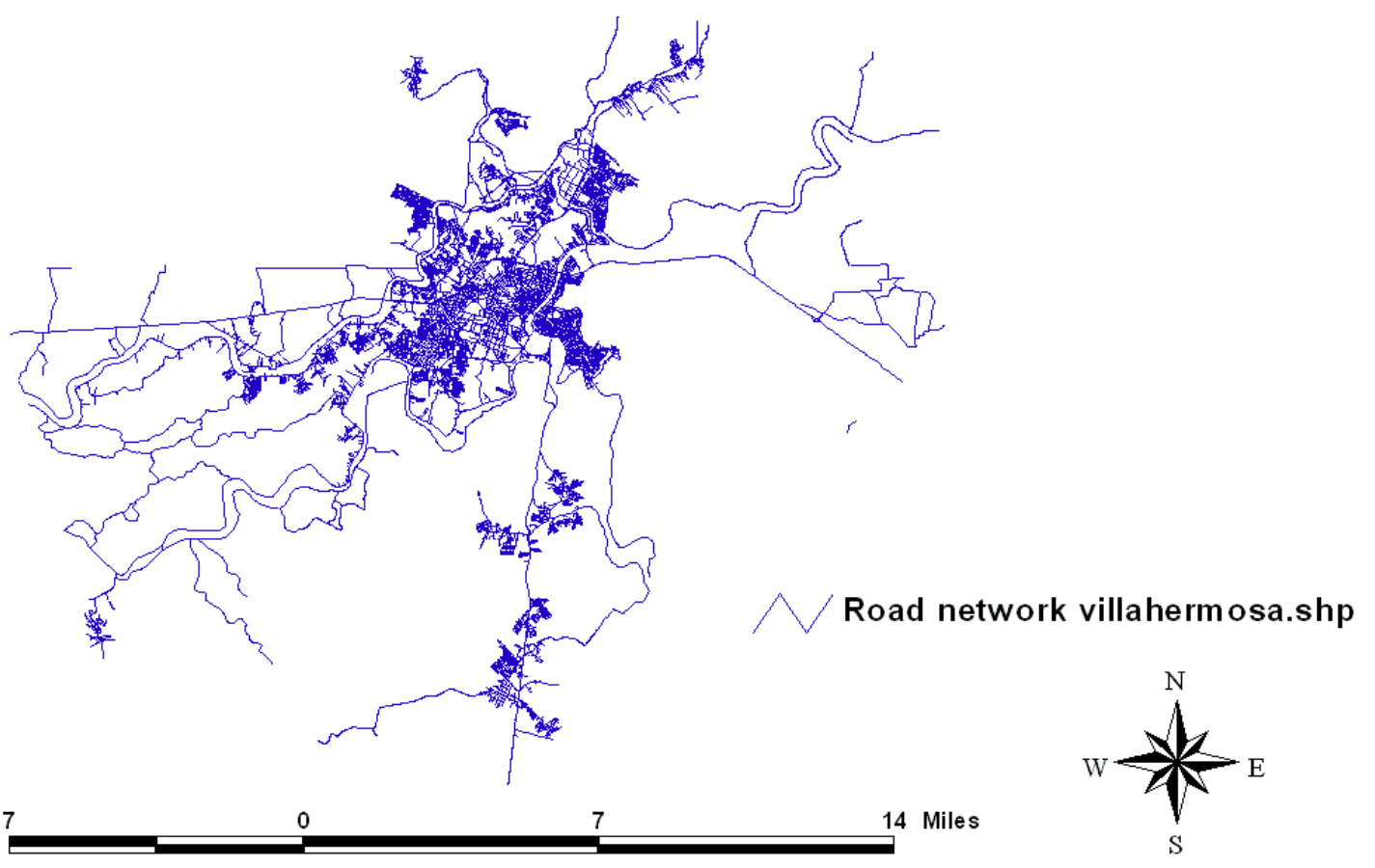

Figure 11. Road network of Villahermosa. Source: Compiled by author with information from INEGI [79]. 


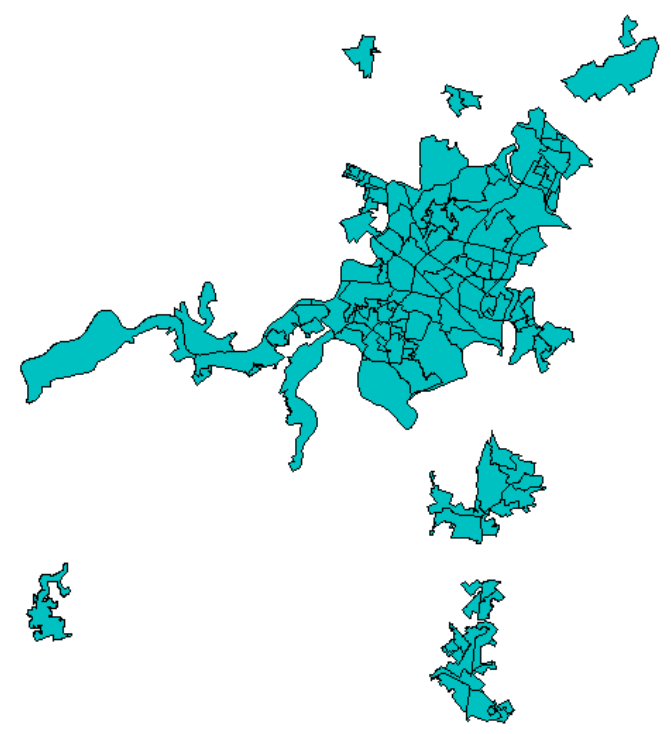

7 0

14 Miles

\section{Agebs villahermosa.shp}

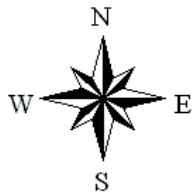

Figure 12. AGEBs existent on Villahermosa. Source: Compiled by author with information from INEGI [79].

After comparison with a DEM provided by INEGI [82], the layer from USGS [80] showed in Figure 13 was selected for analysis.

The catalogue of emergency facilities of the city contained 107 shelters with a total capacity of 26,380 people [71], whereas the reported number of people sheltered was around 99,000 people, see $[70,96,97]$. In reality, insufficient capacity from planned shelters caused authorities to improvise using any facility available including particular houses [96].

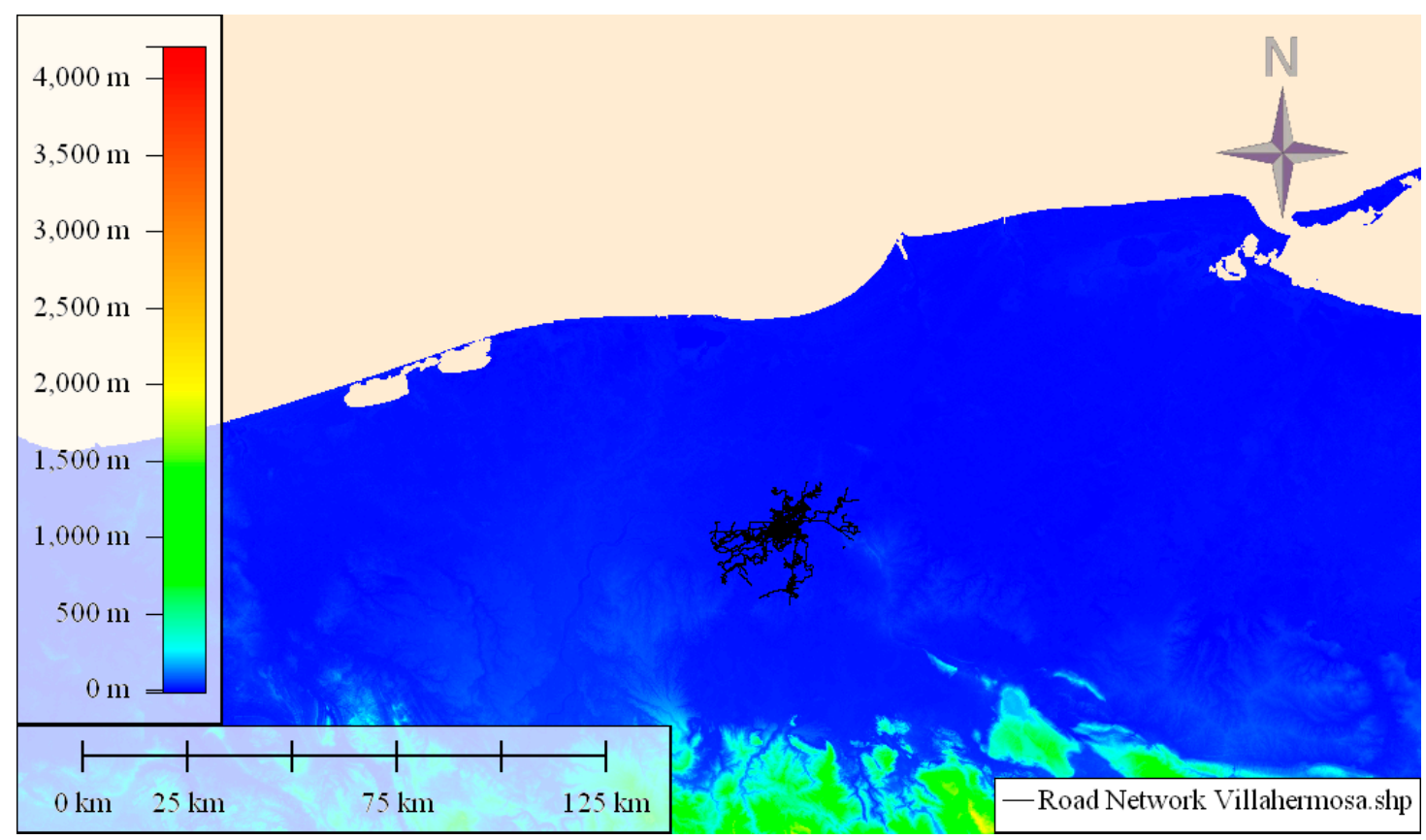

Figure 13. Digital elevation model of Villahermosa. Source: Compiled by author with information from USGS [80]. 
Focusing on the planning component of this project and guidelines from SEDENA [89], a list of suitable shelters from public facilities in the city was obtained. The list was provided by the research group "Modelación de Sistemas Logísticos y de Transporte" (MOSILTRA) from the Universidad Autónoma del Estado de México. It was created using satellite images with a scale of 1:50,000 of the area, and using TransCAD ${ }^{\circledR}$ to draw the area of every facility. The list contains georeferenced data of 1778 facilities in the city including name, type of facility, location and area. After erasing duplicated entries and filtering by type of building and capacity, a list of 443 shelters with an aggregated capacity of 164,253 people was used.

Regarding DCs, the list included one available facility from the Social Development Secretariat (SEDESOL) and 13 public buildings provided by MOSILTRA. Capacities were calculated using the area of the facility.

An overlap of the layer of shelters and the layer of DCs over the road network can be seen on Figure 14, displaying an even distribution across the region.

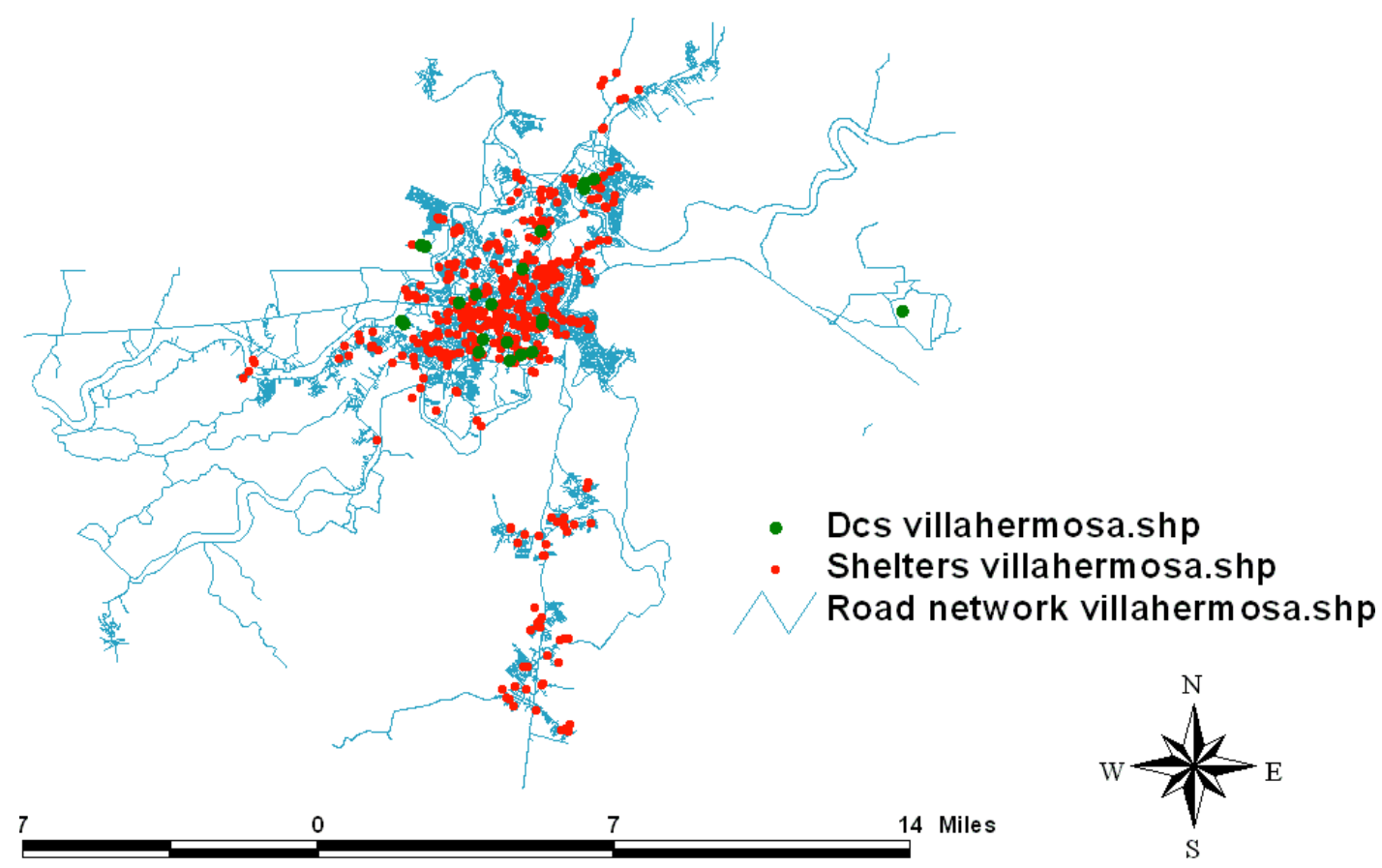

Figure 14. Location of the facilities available in the road network of the Villahermosa region.

\subsubsection{GIS Procedure for the Case of Villahermosa}

Even though the altitude of the city is stated as $10 \mathrm{~m}$ above sea level [91], tests were run ranging from 0 to $20 \mathrm{~m}$ to identify the altitude where the DEM resembled the actual area, obtaining the result around $6 \mathrm{~m}$.

The estimated height of water around $4 \mathrm{~m} \mathrm{[69]} \mathrm{was} \mathrm{used} \mathrm{for} \mathrm{the} \mathrm{creation} \mathrm{of} \mathrm{a} \mathrm{situation} \mathrm{representing}$ the real conditions. The other two scenarios were based on conditions resembling other situations registered in the region, see [93]. The situations selected for Villahermosa were floods of 1, 2 and $4 \mathrm{~m}$.

Applying the cartographic model to the three situations, the images shown in Figure 15 were obtained. 

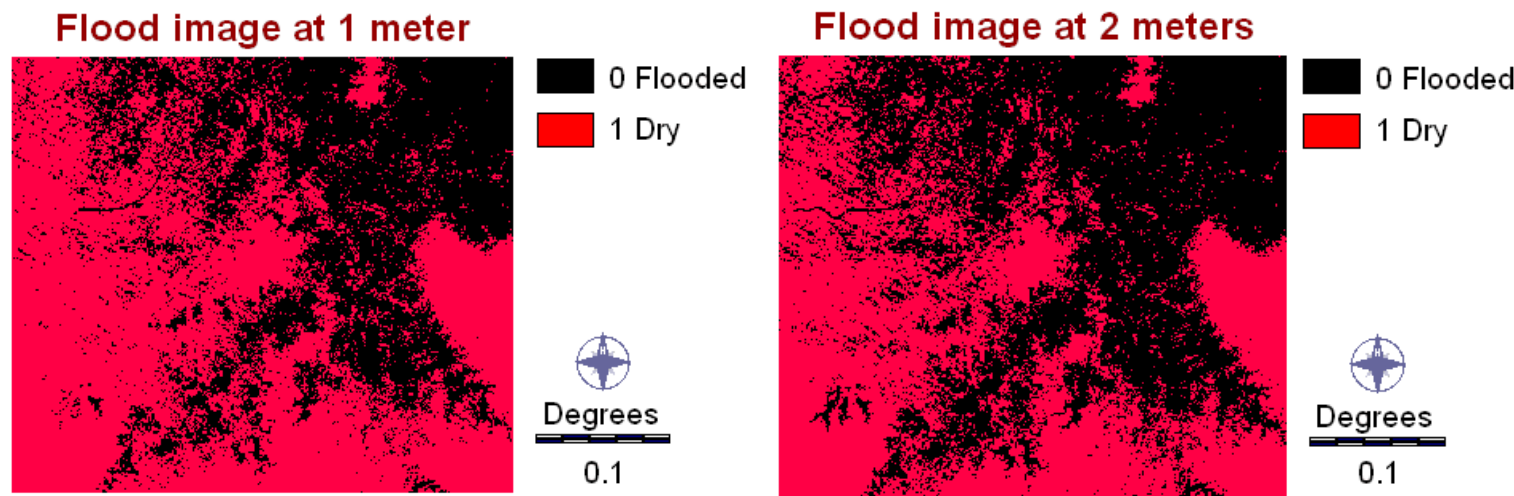

Flood image at 2.5 meters
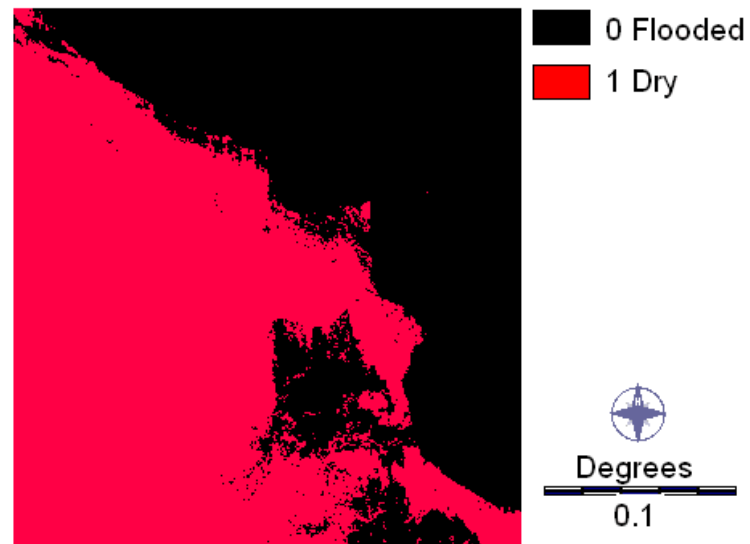

Figure 15. Floods of $1 \mathrm{~m}, 2 \mathrm{~m}$ and $4 \mathrm{~m}$ at Villahermosa.

\subsubsection{Results of the GIS Procedure Applied to Villahermosa}

Figure 16 displays the surviving candidate facilities under the three scenarios, showing the steep effect caused by the flood.

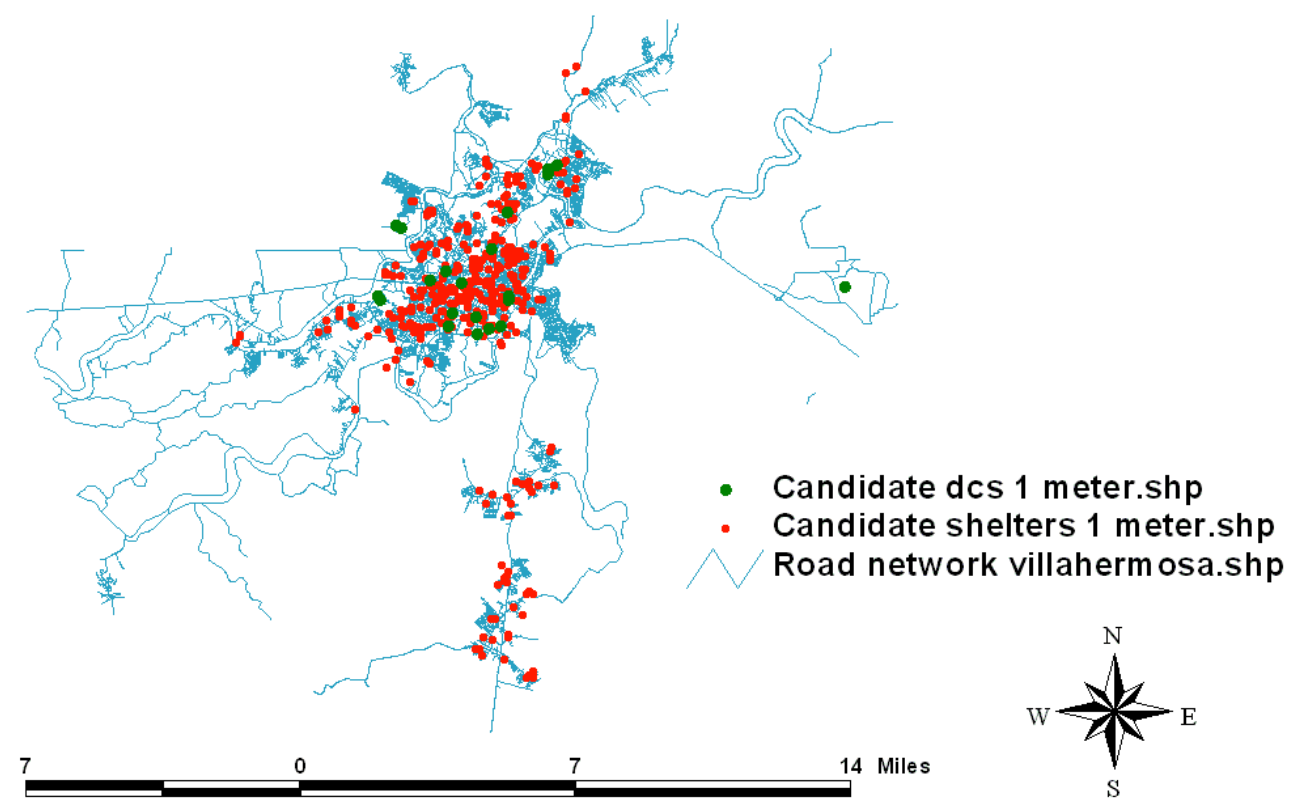

Figure 16. Cont. 


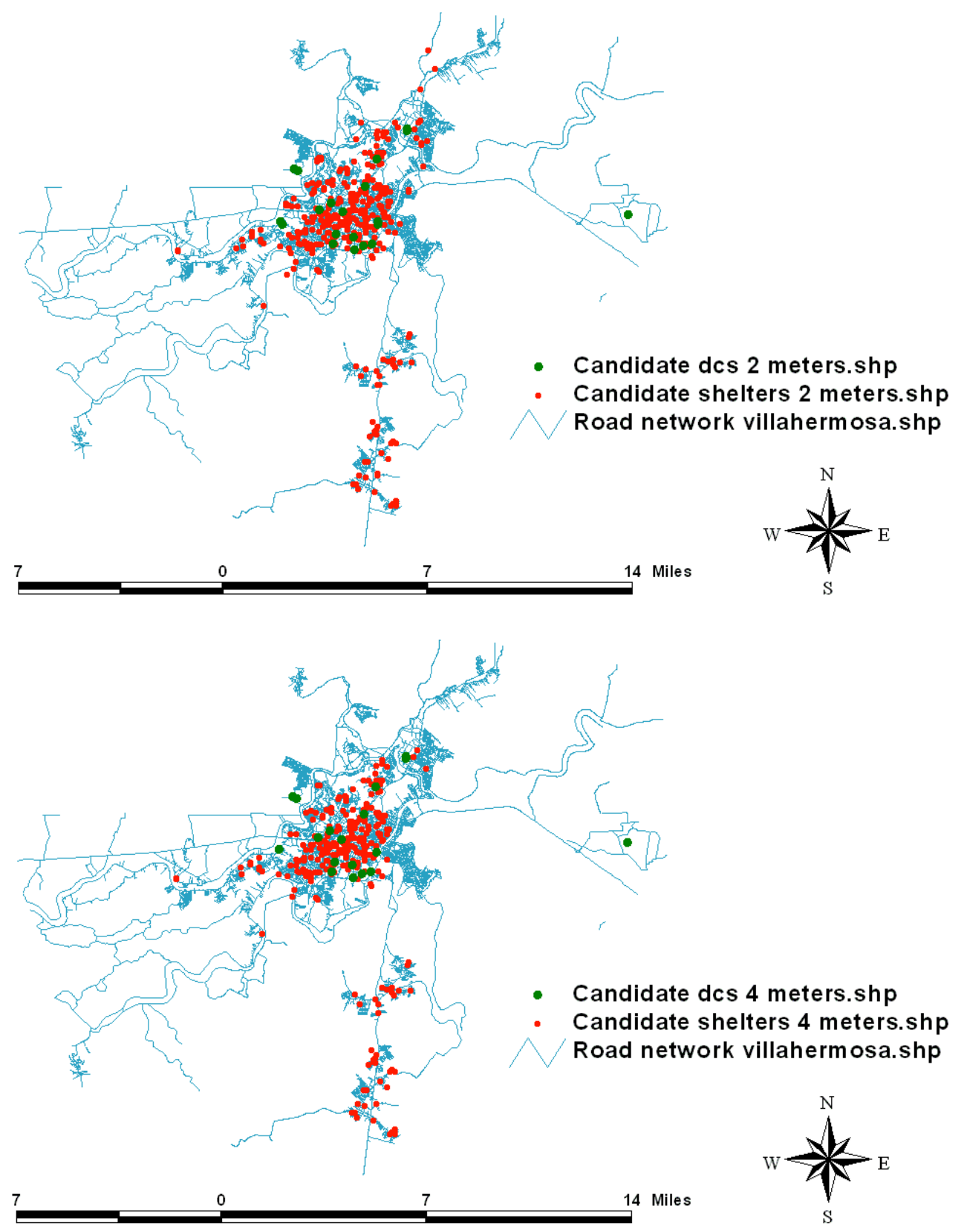

Figure 16. Surviving facilities for floods of $1 \mathrm{~m}, 2 \mathrm{~m}$ and $4 \mathrm{~m}$ at Villahermosa.

A total of 368 candidate shelters survived the flood of one meter, there were 340 remaining shelters for a flood of $2 \mathrm{~m}$ of depth, and a number of 282 shelters survived the situation of $4 \mathrm{~m}$ of height of water. Similarly, for DCs there were 22 surviving facilities for the flood of $1 \mathrm{~m}, 20$ for the flood of $2 \mathrm{~m}$ and 18 for the worst conditions.

Table 5 summarises the damage caused by the floods. Around $68 \%, 78 \%$ and $88 \%$ of the AGEBs were affected by the floods of $1 \mathrm{~m}, 2 \mathrm{~m}$ and $4 \mathrm{~m}$, respectively.

Road connectivity between facilities was determined using the flood maps of the three scenarios along with the Floyd-Warshall algorithm. Connectivity for boat transportation was considered as opposite values from road transportation, and air transportation was considered available between all points. 
Table 5. Summary of level of damage caused by the three scenarios in Villahermosa.

\begin{tabular}{cccc}
\hline Level of Damage & $\mathbf{1} \mathbf{~ m}$ & $\mathbf{2} \mathbf{~ m}$ & $\mathbf{4} \mathbf{~ m}$ \\
\hline Not affected & 47 & 32 & 18 \\
$1<\mathrm{x}<10$ & 35 & 27 & 14 \\
$10<\mathrm{x}<20$ & 10 & 12 & 8 \\
$20<\mathrm{x}<30$ & 13 & 13 & 11 \\
$30<\mathrm{x}<40$ & 11 & 7 & 6 \\
$40<\mathrm{x}<50$ & 6 & 16 & 3 \\
$50<\mathrm{x}<60$ & 6 & 8 & 15 \\
$60<\mathrm{x}<70$ & 7 & 8 & 12 \\
$70<\mathrm{x}<80$ & 4 & 6 & 10 \\
$80<\mathrm{x}<90$ & 0 & 6 & 13 \\
$90<\mathrm{x}$ & 8 & 12 & 37 \\
\hline
\end{tabular}

\subsection{Validation}

The cartographic model was used to include the geographical dimension of the disaster in the analysis. The procedure used for this research comes from the work developed by Martin [21] and extended by Rodríguez-Espíndola and Gaytán [22]. Therefore, the goal is not to propose a new procedure per se, but to show the value of using GIS that can be integrated with optimisation models. In order to show the reliability of the method selected to obtain flood maps, validation of the images derived from the geographical procedure were desired. In this part, each one of the flood maps obtained is analysed considering real conditions to provide a judgement about the outcome of the geographical procedure.

\subsubsection{GIS for the Case of Veracruz}

Using the webpage of the Earth Observatory from NASA [98], a MODIS (Moderate Resolution Imaging Spectroradiometer) from aircraft Terra of 18 September was obtained. The image of the flood is contrasted with another one from 17 September 2009 in Figure 17, to provide some context about the area and to understand better the impact of the flood.
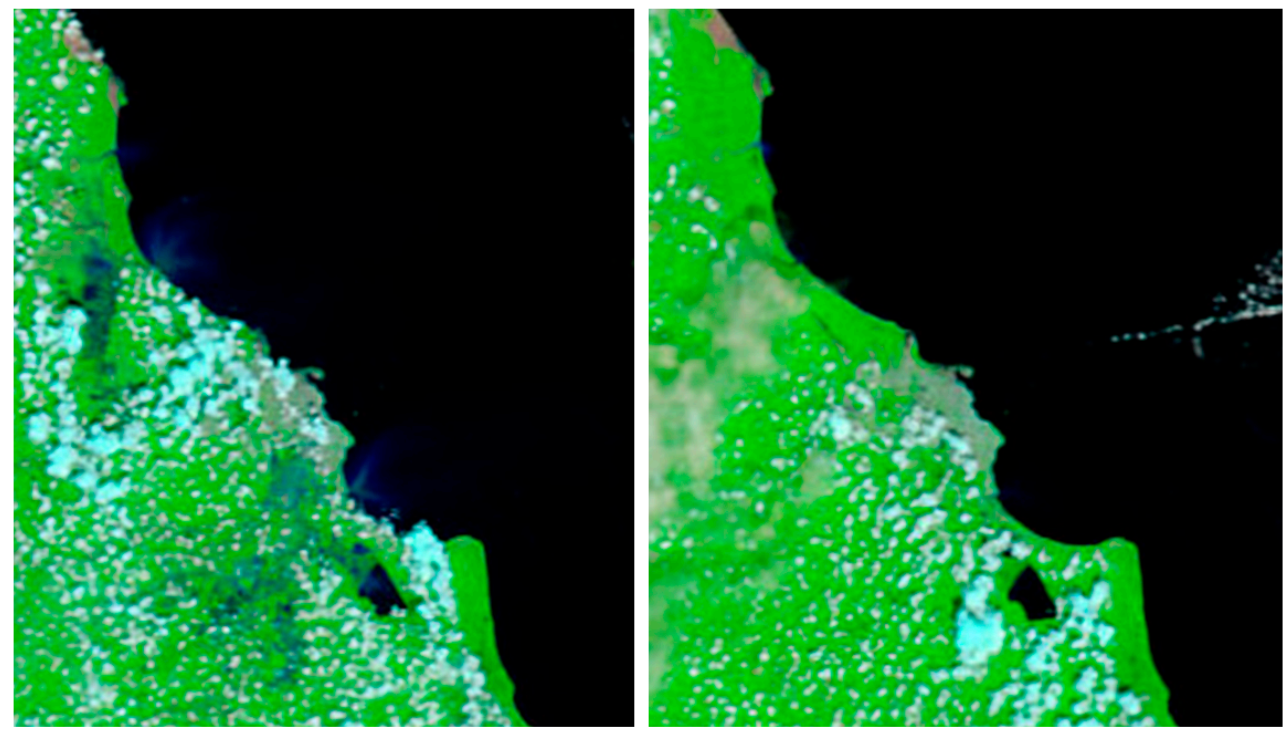

Figure 17. MODIS image from the Terra Satellite of the southeast region of Mexico on 20 September, 2010. Source: NASA [98]. 
Navy blue (dark color) represents the flood in the region, with damage close to the section "Laguna Real". Importing the image into IDRISI ${ }^{\circledR}$ and enhancing its contrast, Figure 18 shows the comparison of the real flood in the region Veracruz-Boca del Río and the results of the geographical procedure employed in this research. The flooded area is very similar in both shape and extension in the centre and south of the region, although the image obtained in this research showed slightly more damage on the west side of the region than the real photograph. Also, a non-existent 'disconnection' of the "San Juan de Ulua" fortress up on the north was identified.

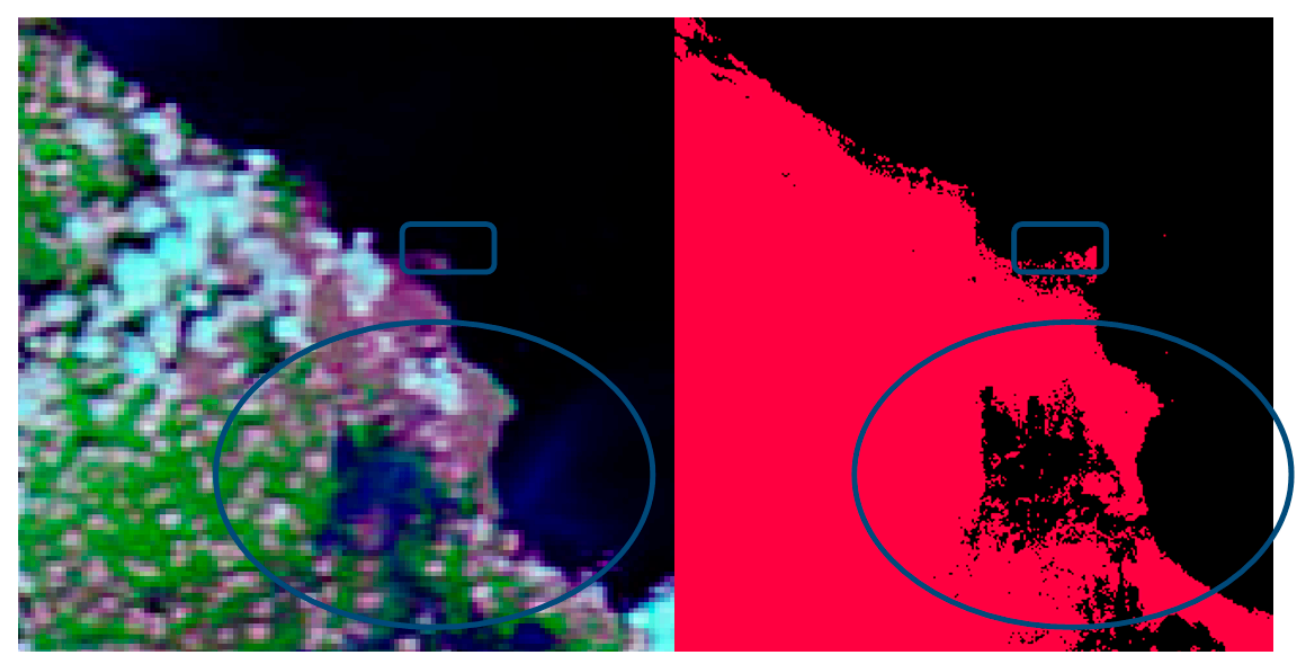

Figure 18. Comparison of the flood map obtained and the real flood in Veracruz, 2010. Source: NASA [98].

Overall, the system provided an image that resembled the actual flood according to the image presented; therefore, the results were deemed appropriate to continue with the analysis.

\subsubsection{GIS for the Case of Villahermosa}

The flood in Villahermosa covered a large proportion of the city and the State. Flood masks from SEMAR [99] and CENAPRED [100] were used for the analysis. Assuming the areas identified by each one of the authorities were flooded at certain point, facilities located in these regions were assumed to get flooded at some moment and thereby eliminated. Looking at Figure 19, the results from the cartographic model resembled the combination of both flood masks provided by the government except for an area in the northwest. There are clear false positives and small areas with false negatives, but the area in the centre (the city) seems to comply with the actual event according to SEMAR and CENAPRED. 

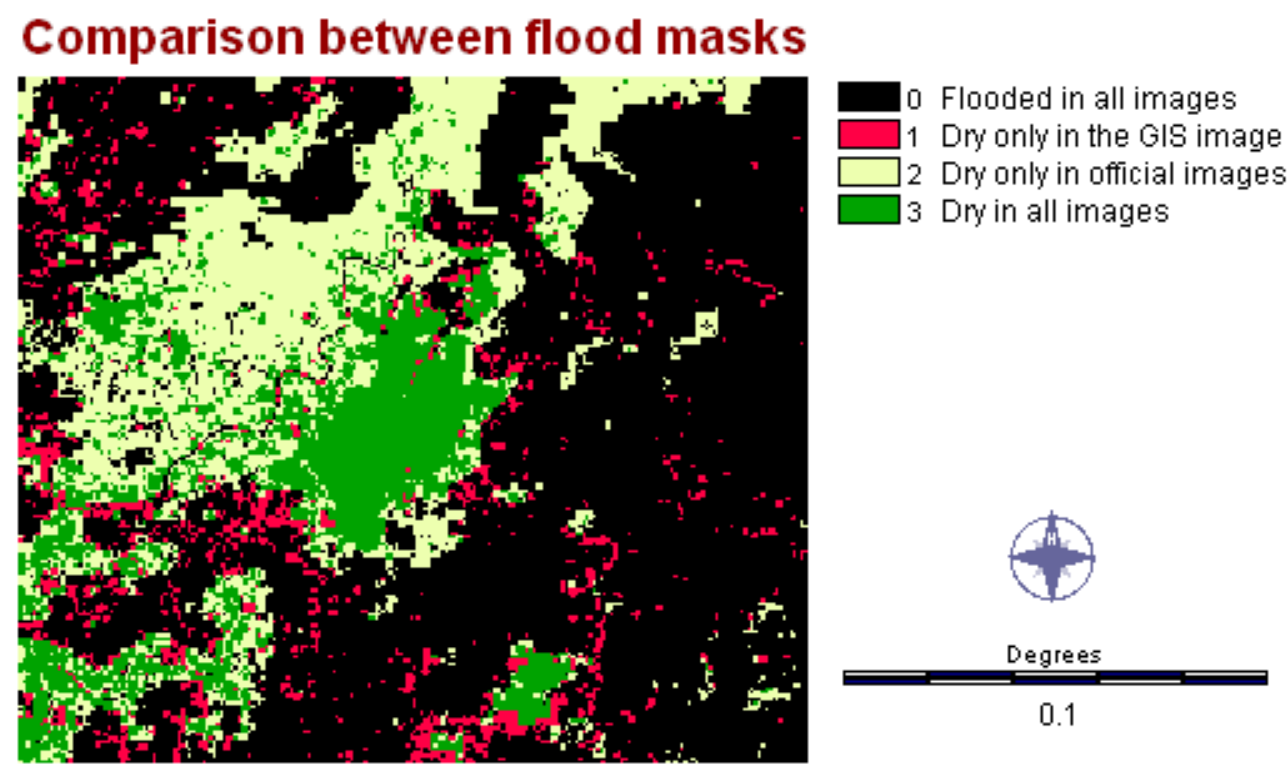

Figure 19. Overlap of the images from authorities with the GIS result for Villahermosa. Source: Compiled by author with information from SEMAR [99], CENAPRED [100] and USGS [80].

Authorities developed a representation of the flood created based on a digital elevation model from Hernández et al. [101]. This representation is compared in Figure 20 with the result from the procedure used. Both images exhibit a very similar shape except for the false positive already discussed in a region of the west, and another in the northeast ("Medellin y Pigua 3a Sección").

There are very few false negatives that are not affecting any of the facilities identified in this study. However, constant false positives presented in the northwest of the city along with the partial flooding of the neighbourhood in the northeast evidence some limitations of the procedure to be addressed in future work. The false positives affected a total of 27 facilities according to the flood masks from authorities. Bearing in mind the purpose of the cartographic model, it can be argued that the overall resemblance of the image produced in this research with the flood masks provided by authorities suggest that the GIS procedure produced an acceptable representation of the flood.

\section{Flood image at 4 meters}
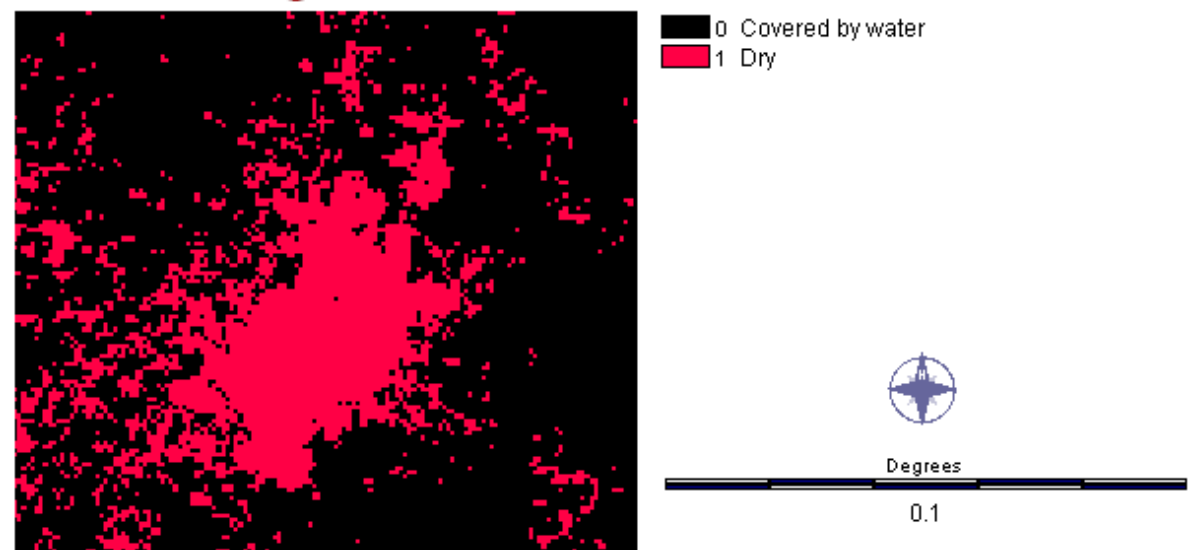

Figure 20. Cont. 


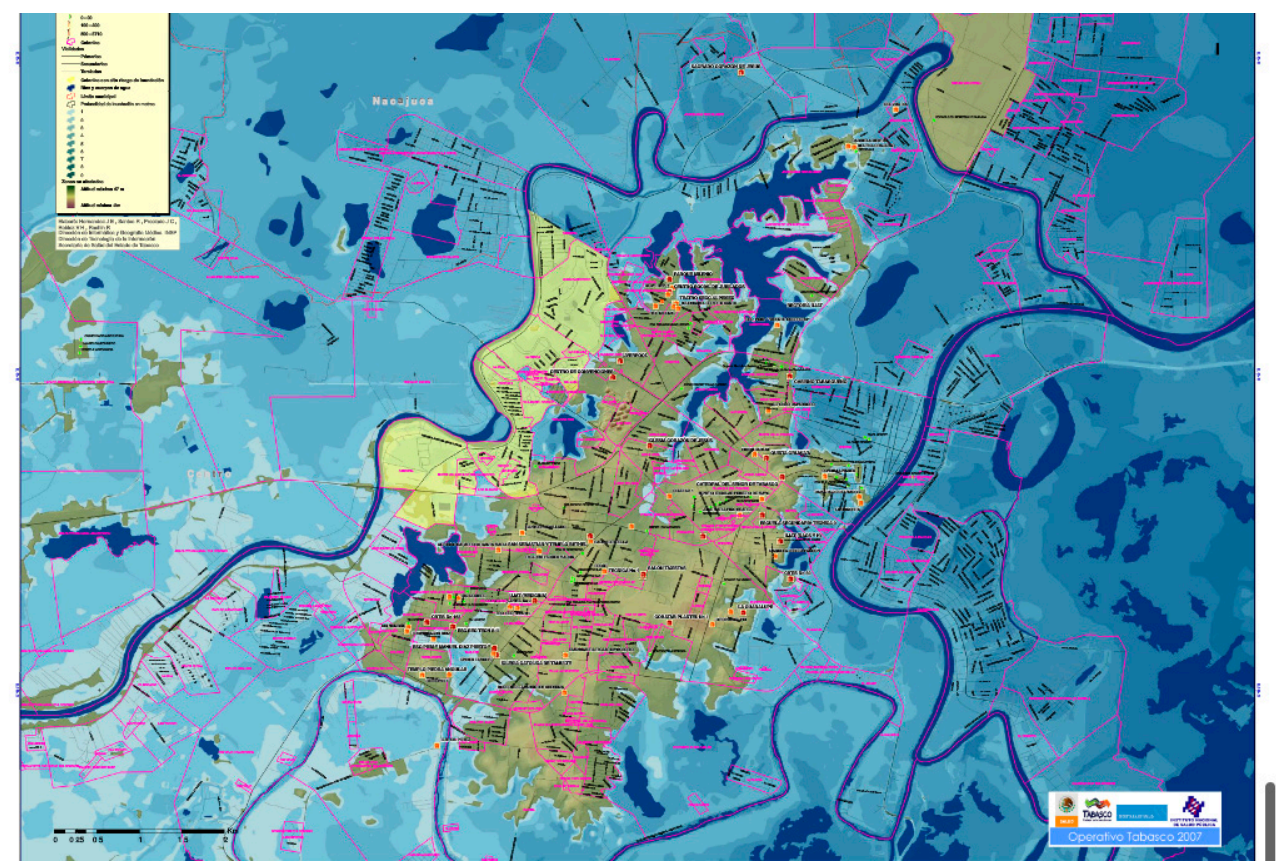

Figure 20. Comparison Comparison representation of the flood from the Health Ministry and the image from the GIS for the flood of 2007 in Villahermosa. Source: Compiled by author with information from Hernández, et al. [101].

\subsubsection{Discussion and Summary of the Results from the Geographical Procedure}

The maps created showed a tendency to overestimate the actual flood. That is related to the underpinning assumption using altitude as a static baseline for the analysis and disregarding more dynamic factors such as runoff. Having false positives can be a challenge for the user, although the very sporadic appearance of false negatives is a good indication. The procedure eliminated facilities that were not flooded; however, there were no surviving facilities that were in reality in floodable areas. In that sense, the process successfully ruled out potentially endangered facilities.

In the maps obtained, the geographical procedure identified the source of the flood and the evolution of it. The maps contained the main areas flooded in each one of the cities. Moreover, the outline of the flooded estimations seems to be consistent with the actual mask of the flood.

It is important to highlight how challenging validation was for the cases at hand. Flood maps from authorities were contradicted by satellite images and pictures from the event for the first case, whereas no images of the critical day of the flood for the case of Villahermosa were found. Fortunately, the flood masks provided by authorities in the last case seemed more realistic, although considerable differences were identified even among them. Therefore, more emphasis ought to be placed on the development of flood masks and satellite pictures to support future work in the area.

\section{Comparison to the Real Circumstances}

GIS for disaster management has a lot of potential because of the inherent benefits of incorporating the physical dimension of the disaster. Nonetheless, to date, most articles in humanitarian logistics incorporating GIS are focusing on network analysis and data display. Cova [18] provided examples of GIS capabilities to provide support in decision-making, but the absence of studies on humanitarian logistics involving GIS motivated this work.

The goal of this paper is to investigate analytically the way the use of GIS to analyse the flood situation could affect decision-making for facility locations. The results of the cases presented in the previous section were introduced and solved for the model developed by Rodríguez-Espíndola, 
Albores and Brewster [40], and then contrasted with the same model running without the input from the GIS. The information required by the model broadly includes costs, personnel available, vehicles available, relief items available, capacity of facilities, and number of sheltered people per demand area. The above information should be provided per organisation, including all of the organisations involved in the logistical deployment after the flood. Databases can be created combining the information enumerated with the results provided by the GIS procedure, to solve the optimisation model.

For the case of Veracruz, a total of 62 requests were filed to a total of seven agencies involved in disaster management in the area, whereas 121 requests were made to 10 national governmental bodies also involved in the flood. A total of nine operational agencies were identified as primary actors in the field. The agencies included were: DICONSA, National System of Family Development (DIF), Social Security Mexican Institute (IMSS), Civil protection (PC), National Health Ministry (SMEXICO), State Health Ministry of Veracruz (SVERACRUZ), the Military (SEDENA), Ministry of Interior (SEGOB) and the Navy (SEMAR).

For the flood in Villahermosa, 128 freedom of information (FOI) requests were sent to nine National authorities and 134 requests were filed to eight regional authorities. Among the 17 agencies enquired, 13 agencies were included for the case. These were Municipality, DICONSA, DIF, IMSS, Social Security Institute of the State of Tabasco (ISSET), PC, SMEXICO, State Health Ministry of Tabasco (STABASCO), Transport and Communications Secretariat (SCT), SEDENA, SEGOB, SEMAR and the Safety and Security Secretariat (SSP).

All of the instances presented here were solved using GAMS ${ }^{\circledR}$ with Cplex ${ }^{\circledR}$ as a solver on a desktop with an Intel i7 processor and 16 GB of RAM.

\subsection{Veracruz}

The optimisation model was applied to the region of Veracruz-Boca del Río for 50 iterations. All of the available facilities were introduced assuming perfect connectivity between them. The $\varepsilon$-constraint method and weighted-sum method were applied to solve the bi-objective optimisation model. Because of the complexity of disaster management, the purpose of the model is not only to minimise cost, but also to maximise the level of service provided to disaster victims. The combination of two performance measures being optimised simultaneously provides several solutions, from which the decision-maker has to select the preferred one.

The difference between the solutions in terms of the performance measures obtained can be seen in Figure 21. Each one of the points showed is called a non-dominated solution, which for this case means that there is no other combination in the feasible space that is better on both cost and level of service. Every one of the points shown in the graph represents a policy including the list of facilities to use, as well as the decisions related to stock prepositioning and relief distribution. For the purposes of this research, only the result of the performance measures (cost and level of service) is shown, to demonstrate the way the results of the GIS can affect the metrics of the logistical activities performed by authorities.

The result shows no significant difference in the Pareto frontier obtained from the system designed compared to the stand-alone application of the model. Looking at the numbers, only one solution showed an improvement around $1 \%$ in fill rate, whereas for the rest the change was considerably smaller or non-existent. 


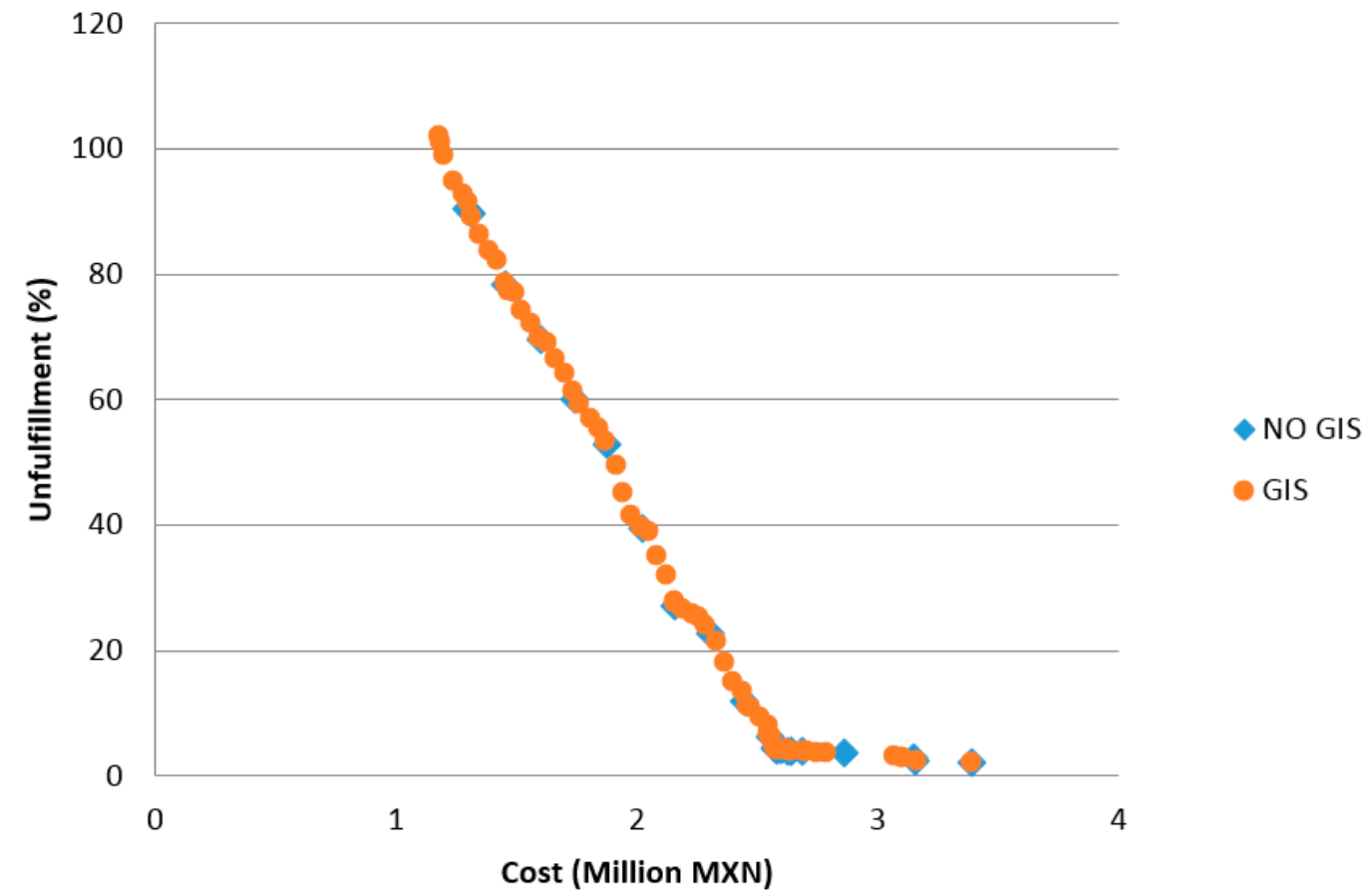

Figure 21. Comparison between the results for Veracruz-Boca del Río with and without GIS.

Table 6 shows the number of endangered facilities included in each one of the solutions obtained disregarding the use of the GIS. A little over $58 \%$ of the solutions are not including potentially flooded shelters whilst over $83 \%$ are not considering endangered DCs; which means that overall only $54.17 \%$ of the solutions obtained did not considered potentially affected facilities.

Table 6. Floodable number of facilities selected per scenario in Veracruz.

\begin{tabular}{cccccc}
\hline ID & Cost (mxn) & Unfulfilled (\%) & Shelters Endangered & People at Risk & DCs Affected \\
\hline VNG1 & $1,289,382.25$ & 90.57 & 2 & 568 & 1 \\
VNG2 & $1,314,943.16$ & 89.71 & 3 & 615 & 1 \\
VNG3 & $1,457,745.88$ & 78.26 & 1 & 62 & 0 \\
VNG4 & $1,596,843.04$ & 69.57 & 2 & 224 & 1 \\
VNG5 & $1,738,612.65$ & 60.23 & 1 & 282 & 0 \\
VNG6 & $1,879,685.44$ & 52.82 & 2 & 352 & 0 \\
VNG7 & $2,020,920.35$ & 39.5 & 2 & 490 & 0 \\
VNG8 & $2,161,081.47$ & 27.18 & 2 & 568 & 0 \\
VNG9 & $2,302,564.41$ & 22.6 & 0 & 0 & 0 \\
VNG10 & $2,443,454.81$ & 11.84 & 0 & 0 & 0 \\
VNG11 & $2,550,565.24$ & 6.22 & 2 & 565 & 0 \\
VNG12 & $2,572,117.95$ & 4.46 & 0 & 0 & 0 \\
VNG13 & $2,577,332.72$ & 4.37 & 0 & 0 & 0 \\
VNG14 & $2,578,529.58$ & 4.33 & 0 & 0 & 0 \\
VNG15 & $2,584,964.49$ & 4.29 & 0 & 290 & 0 \\
VNG16 & $2,602,335.43$ & 4.21 & 1 & 0 & 0 \\
VNG17 & $2,625,476.88$ & 4.12 & 0 & 0 & 0 \\
VNG18 & $2,636,437.79$ & 4.07 & 0 & 0 & 0 \\
VNG19 & $2,639,966.91$ & 4.03 & 0 & 0 & 0 \\
VNG20 & $2,689,884.41$ & 3.86 & 0 & 0 & 0 \\
VNG21 & $2,862,202.03$ & 3.75 & 0 & 0 & 0 \\
VNG22 & $3,142,947.2$ & 2.87 & 0 & 0 & 0 \\
VNG23 & $3,157,023.09$ & 2.43 & 0 & 0 & \\
VNG24 & $3,388,740.71$ & 2.16 & 0 & 0 &
\end{tabular}


The difference between the flood map obtained in this research and the actual flood did not affect any facilities. The conclusion is that neglecting the GIS would generate insignificant improvements in terms of cost and service. However, the probability of wrongfully opening a facility when disregarding the GIS, particularly shelters, is something that should be considered.

\subsection{Villahermosa}

In Figure 22, the variation from the model considering the GIS results and the model disregarding such results is noticeable. Particularly between $30 \%$ and $50 \%$ of fill rate, the results without GIS have considerable improvements in terms of both cost and fill rate. The solution delivered by the system can be improved by up to $8.44 \%$ of fill rate if the results of the GIS are not considered.

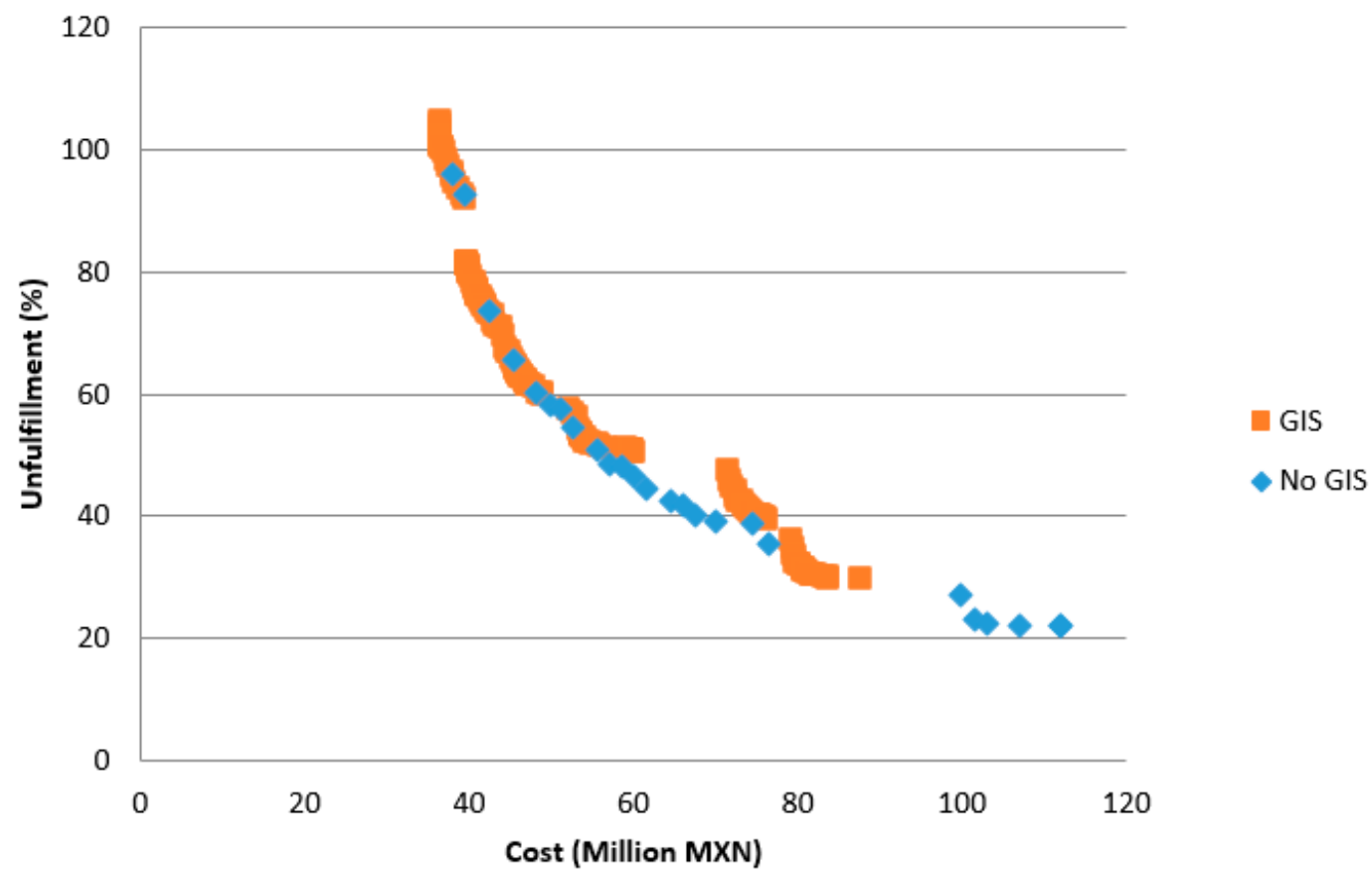

Figure 22. Comparison between the results for Villahermosa with and without GIS.

Table 7 exhibits the number of potentially endangered facilities included in each one of the solutions. With $100 \%$ of the solutions selecting potentially undesirable shelters and $52 \%$ choosing endangered DCs, all of the solutions obtained in the model disregarding the GIS results used at least one floodable facility. More importantly, the number of people potentially in danger of being allocated in a flooded facility is on average $30 \%$ of total demand.

A very large number of people could be affected in case the results from the geographical procedure would be disregarded considering only the potential improvements. The maximum improvement obtained by disregarding the GIS is $8.44 \%$ of fill rate, with around 8358 potentially benefited people. Nonetheless, the 104 facilities in risky areas would endanger 33,713 people.

Commenting in terms of the false positives outside of the city, out of the 160 shelters discarded by the flood using the image from SEMAR [99], a total of 27 shelters were wrongfully ruled out. For effects of the conclusion, as the 27 shelters have a joint capacity of 13,135 people, in the case that all of these shelters are selected and are operating at full capacity; still the improvements would not reach the number of people at risk. 
Table 7. Floodable number of facilities selected per scenario in Villahermosa.

\begin{tabular}{cccccc}
\hline ID & Cost $(\mathbf{m x n})$ & Unfulfilled (\%) & Shelters Endangered & People at Risk & DCs Affected \\
\hline TNG1 & $37,912,695$ & 95.79288 & 60 & 34,577 & 0 \\
TNG2 & $39,393,530$ & 92.64069 & 55 & 27,214 & 0 \\
TNG3 & $42,348,714$ & 73.58491 & 59 & 31,891 & 0 \\
TNG4 & $45,312,141$ & 65.80087 & 62 & 31,285 & 0 \\
TNG5 & $48,281,093$ & 60.11983 & 61 & 31,285 & 0 \\
TNG6 & $49,754,160$ & 58.25243 & 73 & 32,612 & 0 \\
TNG7 & $51,202,469$ & 57.53509 & 66 & 32,013 & 0 \\
TNG8 & $52,724,503$ & 54.55939 & 65 & 29,499 & 0 \\
TNG9 & $55,651,605$ & 51.02041 & 89 & 37,790 & 0 \\
TNG10 & $57,165,905$ & 48.65591 & 55 & 27,135 & 0 \\
TNG11 & $58,648,895$ & 48.3871 & 38 & 33,539 & 1 \\
TNG12 & $60,125,523$ & 46.58491 & 60 & 34,196 & 1 \\
TNG13 & $61,601,567$ & 44.54685 & 60 & 37,175 & 0 \\
TNG14 & $64,412,961$ & 42.46285 & 80 & 29,620 & 1 \\
TNG15 & $66,035,112$ & 41.97531 & 82 & 31,636 & 1 \\
TNG16 & $67,533,346$ & 40.23379 & 89 & 29,885 & 1 \\
TNG17 & $70,001,418$ & 39.17713 & 104 & 33,713 & 2 \\
TNG18 & $74,611,184$ & 38.61004 & 106 & 30,080 & 3 \\
TNG19 & $76,422,606$ & 35.58719 & 88 & 33,701 & 1 \\
TNG20 & $99,705,500$ & 27.14364 & 85 & 30,618 & 0 \\
TNG21 & $101,569,322$ & 23.00877 & 79 & 30,336 & 1 \\
TNG22 & $102,882,459$ & 22.32704 & 96 & 32,566 & 2 \\
TNG23 & $106,992,320$ & 22.2973 & 94 & 29,230 & 2 \\
TNG24 & $111,912,735$ & 22.25476 & 160 & 34,849 & 3 \\
TNG25 & $111,979,634$ & 22.05567 & 160 & 31,306 & 2 \\
\hline
\end{tabular}

\subsection{Summary and Discussion}

As could be expected, the increase in the flood magnitude also leads to a change in the impact the GIS can have on the result. For the "small case" selected, Veracruz showed a significant number of solutions incorporating facilities at risk with insignificant improvements.

The situation in Villahermosa provides the best example of the value of the GIS. There were improvements by up to $8.44 \%$ of fill rate, but with nearly a third of people at risk. Moreover, the operation can become notably more costly if the expenditure of opening floodable facilities is combined with the cost of relocating people and activating different facilities (if available). In fact, in Villahermosa there were reports of flooded facilities and people relocated in 2007 [102,103].

The use of a tool such as the GIS procedure applied in this research can provide better information for decision-making. Even though the flood maps showed an overestimation of the flood in the case of Villahermosa, the results in this section stand because of the risk that can be potentially avoided by the application of the procedure.

According to the results, in disasters with a low number of facilities affected, the improvements gained by disregarding the physical conditions of the event are minimal compared to their inclusion, and, at the same time, higher risk is incurred. On the other hand, a test on a large-scale disaster is showing that, even if mistakes in the prediction are accounted for, the risk of using a solution without considering the physical dimension of the event is considerably larger than the potential benefits.

\section{Conclusions}

Despite the ongoing recent developments in the use of GIS for disaster management, e.g., [104-106], the common trend in humanitarian logistics is to employ these systems for data visualisation and network analysis rather than emergency analysis [107]. Considering the potential of these tools to support other activities [18], it is important to investigate the value of embedding GIS in an optimisation-based disaster management system to draw conclusions based on empirical results. 
This type of test has not been undertaken before in the literature, and it can deliver interesting insights about the incorporation of GIS for future analytical tools for flood management.

An experiment for two cases under real circumstances was set-up to address this question. The instances considered scenarios with and without the use of GIS. The purpose was to identify potential benefits and drawbacks generated by the use of these kinds of systems.

For the case of Veracruz, potential improvements in the performance measures when not using GIS were minimal whilst several solutions included floodable facilities potentially affecting hundreds of people. The case of Villahermosa showed significant advantages of disregarding the system. Nonetheless, the number of people endangered was on average nearly a third of the total number of victims. Therefore, the potential benefits of dismissing the system were outweighed by the risk implied by doing so. Moreover, putting people in a floodable facility duplicates cost (opening two different facilities for the same people), requires relocation, creates delays in relief aid delivery (as the status of people is unknown until they are settled), and carries the possibility of having to improvise facilities or leaving people without protection.

Overall, GIS can reduce risk for disaster victims, potentially making a significant positive difference in disaster management. According to the results obtained, the risk of disregarding the GIS can go far beyond the expected benefits.

Even though there is an increase in the use of GIS for humanitarian logistics in recent years, the percentage of papers employing these systems for analysing the situation is still relatively small. The empirical results from this research can serve to support the argument that incorporating GIS systems in decision-making for disaster management is very important, reducing considerably the risk of wrongfully selecting facilities located in floodable areas.

Similar to the results of this paper, there are relevant efforts in the literature showing other capabilities of GIS not only to analyse the flood but to incorporate real-time information in decision making. It is our belief that the development and exploitation of these capabilities constitute very fruitful streams of research for future systems.

Acknowledgments: The corresponding author wants to acknowledge financial support from Consejo Nacional de Ciencia y Tecnología (CONACYT) and Aston University for the development of this research.

Author Contributions: The three authors contributed equally to the development of this paper. The research was conceived and designed by the three authors, carried out by the corresponding author, and supervised and revised by the remaining authors. The paper was written by the corresponding author and edited by the remaining authors.

Conflicts of Interest: The authors declare no conflict of interests.

\section{References}

1. United Nations International Strategy for Disaster Reduction. Disaster Statistics. Available online: http:/ /www.unisdr.org/we/inform/disaster-statistics (accessed on 13 February 2013).

2. Independent Evaluation Group. Hazards of Nature, Risk to Development. An IEG Evaluation of World Bank Assistance for Natural Disasters; IEG: Washington, DC, USA, 2006; p. 181.

3. Guha-Sapir, D.; Vos, F.; Below, R.; Ponserre, S. Annual Disaster Statistical Review 2011-The Numbers and Trends; Centre for Research on the Epidemiology of Disasters (CRED), Institute of Health and Society (IRSS) and Université catholique de Louvain: Brussels, Belgium, 2012.

4. Cozzolino, A. Humanitarian logistics and supply chain management. In Humanitarian Logistics; Springer: Berlin, Germany, 2012; pp. 5-16.

5. De Leeuw, S.; Vis, I.F.A.; Jonkman, S.N. Exploring logistics aspects of flood emergency measures. J. Conting. Crisis Manag. 2012, 20, 166-179. [CrossRef]

6. Tehrany, M.S.; Pradhan, B.; Jebur, M.N. Spatial prediction of flood susceptible areas using rule based Decision Tree (DT) and a novel ensemble bivariate and multivariate statistical models in GIS. J. Hydrol. 2013, 504, 69-79. [CrossRef] 
7. Ajin, R.S.; Krishnamurthy, R.R.; Jayaprakash, M.; Vinod, P.G. Flood hazard assessment of vamanapuram river basin, Kerala, India: An approach using remote sensing \& GIS techniques. Adv. Appl. Sci. Res. 2013, 4, 263-274.

8. Patel, D.; Srivastava, P. Flood hazards mitigation analysis using remote sensing and GIS: Correspondence with town planning scheme. Water Resour. Manag. 2013, 27, 2353-2368. [CrossRef]

9. Sarhadi, A.; Soltani, S.; Modarres, R. Probabilistic flood inundation mapping of ungauged rivers: Linking gis techniques and frequency analysis. J. Hydrol. 2012, 458-459, 68-86. [CrossRef]

10. Kunz, N.; Reiner, G. A meta-analysis of humanitarian logistics research. J. Humanit. Logist. Supply Chain Manag. 2012, 2, 116-147. [CrossRef]

11. Chang, M.-S.; Tseng, Y.-L.; Chen, J.-W. A scenario planning approach for the flood emergency logistics preparation problem under uncertainty. Transp. Res. Part E Logist. Transp. Rev. 2007, 43, 737-754. [CrossRef]

12. Crowther, K.G. Risk-informed assessment of regional preparedness: A case study of emergency potable water for hurricane response in Southeast Virginia. Int. J. Crit. Infrastruct. Prot. 2010, 3, 83-98. [CrossRef]

13. Altay, N.; Green, W.G. OR/MS research in disaster operations management. Eur. J. Oper. Res. 2006, 175, 475-493. [CrossRef]

14. Diaz, C.; Isuhuaylas, V. Analisis de gran vision de las inundaciones en la cuenca alta del rio lerma: Caso de las subcuenca del rio Tejalpa, Estado de Mexico, Mexico. Ing. Hidrául. Méx. 2001, 16, 73-86.

15. Ward, P.J.; de Moel, H.; Aerts, J.C.J.H.; Glade, T. How are flood risk estimates affected by the choice of return-periods? Nat. Hazards Earth Syst. Sci. 2011, 11, 3181-3195. [CrossRef]

16. Esteves, L.S. Consequences to flood management of using different probability distributions to estimate extreme rainfall. J. Environ. Manag. 2013, 115, 98-105. [CrossRef] [PubMed]

17. Liebscher, S.; Kirschstein, T.; Becker, C. The flood algorithm-A multivariate, self-organizing-map-based, robust location and covariance estimator. Stat. Comput. 2012, 22, 325-336. [CrossRef]

18. Cova, T.J. GIS in emergency management. In Geographical Information Systems: Principles, Techniques, Management and Applications; Longley, P.A., Goodchild, M.F., Maguire, D.J., Rhind, D.W., Eds.; Wiley: New York, NY, USA, 1999; pp. 845-858.

19. Horner, M.W.; Downs, J.A. Testing a flexible geographic information system-based network flow model for routing hurricane disaster relief goods. Transp. Res. Rec. 2007, 2022, 47-54. [CrossRef]

20. Horner, M.W.; Downs, J.A. Optimizing hurricane disaster relief goods distribution: Model development and application with respect to planning strategies. Disasters 2010, 34, 821-844. [CrossRef] [PubMed]

21. Martin, K. Modeling the impact of sea level rise in narraganset bay, rhode island. In Applications in Coastal Research and Management; UNITAR: Geneva, Switzerland, 1993; pp. 59-61.

22. Rodríguez-Espíndola, O.; Gaytán, J. Scenario-based preparedness plan for floods. Nat. Hazards 2015, 76, 1241-1262. [CrossRef]

23. Prathumchai, K.; Samarakoon, L. Application of remote sensing and GIS techniques for flood vulnerability and mitigation planning in munshiganj district of bangladesh. In Proceedings of the 25th Asian Conference on Remote Sensing, Hanoi, Vietnam, 7-11 November 2005.

24. El-Anwar, O.; El-Rayes, K.; Elnashai, A. An automated system for optimizing post-disaster temporary housing allocation. Autom. Constr. 2009, 18, 983-993. [CrossRef]

25. El-Anwar, O.; El-Rayes, K.; Elnashai, A. Multi-objective optimization of temporary housing for the 1994 northridge earthquake. J. Earthq. Eng. 2008, 12, 81-91. [CrossRef]

26. Saadatseresht, M.; Mansourian, A.; Taleai, M. Evacuation planning using multiobjective evolutionary optimization approach. Eur. J. Oper. Res. 2009, 198, 305-314. [CrossRef]

27. Alçada-Almeida, L.; Tralhão, L.; Santos, L.; Coutinho-Rodrigues, J. A multiobjective approach to locate emergency shelters and identify evacuation routes in urban areas. Geogr. Anal. 2009, 41, 9-29. [CrossRef]

28. Coutinho-Rodrigues, J.; Tralhão, L.; Alçada-Almeida, L. Solving a location-routing problem with a multiobjective approach: The design of urban evacuation plans. J. Transp. Geogr. 2012, 22, 206-218. [CrossRef]

29. Chanta, S.; Sangsawang, O. Shelter-site selection during flood disaster. Lect. Notes Manag. Sci. 2012, 4, 282-288.

30. Dekle, J.; Lavieri, M.S.; Martin, E.; Emir-Farinas, H.L.; Francis, R.L. A florida county locates disaster recovery centers. Interfaces 2005, 35, 133-139. [CrossRef] 
31. Tzeng, G.-H.; Cheng, H.-J.; Huang, T.D. Multi-objective optimal planning for designing relief delivery systems. Transp. Res. Part E Logist. Transp. Rev. 2007, 43, 673-686. [CrossRef]

32. Maliszewski, P.J.; Horner, M.W. A spatial modeling framework for siting critical supply infrastructures*. Prof. Geogr. 2010, 62, 426-441. [CrossRef]

33. Widener, M.J.; Horner, M.W. A hierarchical approach to modeling hurricane disaster relief goods distribution. J. Transp. Geogr. 2011, 19, 821-828. [CrossRef]

34. Teixeira, J.C.; Antunes, A.P. A hierarchical location model for public facility planning. Eur. J. Oper. Res. 2008, 185, 92-104. [CrossRef]

35. Salman, F.S.; Yücel, E. Emergency facility location under random network damage: Insights from the istanbul case. Comput. Oper. Res. 2015, 62, 266-281. [CrossRef]

36. Barzinpour, F.; Esmaeili, V. A multi-objective relief chain location distribution model for urban disaster management. Int. J. Adv. Manuf. Technol. 2014, 70, 1291-1302. [CrossRef]

37. Esmaeili, V.; Barzinpour, F. Integrated decision making model for urban disaster management: A multi-objective genetic algorithm approach. Int. J. Ind. Eng. Comput. 2014, 5, 55-70. [CrossRef]

38. Zhao, M.; Chen, Q. Risk-based optimization of emergency rescue facilities locations for large-scale environmental accidents to improve urban public safety. Nat. Hazards 2015, 75, 163-189. [CrossRef]

39. Ahmadi, M.; Seifi, A.; Tootooni, B. A humanitarian logistics model for disaster relief operation considering network failure and standard relief time: A case study on san francisco district. Transp. Res. Part E Logist. Transp. Rev. 2015, 75, 145-163. [CrossRef]

40. Rodríguez-Espíndola, O.; Albores, P.; Brewster, C. A multi-agency perspective to disaster preparedness. In Proceedings of the 12th International Conference on Information Systems for Crisis Response and Management, Kristiansand, Norway, 24-27 May 2015.

41. Radke, J.; Cova, T.; Sheridan, M.F.; Troy, A.; Mu, L.; Johnson, R. Application challenges for geographic information science: Implications for research, education, and policy for emergency preparedness and response. J. Uran Reg. Inf. Sci. Assoc. 2000, 12, 15-30.

42. Van Westen, C.J. Remote sensing and geographical information systems for natural disaster management. In Environmental Modelling with GIS and Remote Sensing; Skidmore, A., Ed.; CRC Press: London, UK, 2002; pp. 211-226.

43. Jian-Kun, H.; Bin, Y.; Jie, W.; Zhi-Huan, W.; Zhi-Hua, H. GIS-based safe area discovery for emergency logistics. In Proceedings of the 2nd IEEE International Conference on Information Management \& Engineering (ICIME), Chengdu, China, 16-18 April 2010; pp. 98-101.

44. Chang, K.-T. Introduction to Geographic Information Systems; McGraw-Hill: Boston, MA, USA; London, $\mathrm{UK}, 2002$.

45. Delaney, J. Geographical Information Systems: An Introduction; Oxford University Press: Oxford, UK, 1999.

46. Tomlin, C.D. GIS and Cartographic modelling. In Geographic Information Systems and Science, 1st ed.; Longley, P., Ed.; Wiley: Hoboken, NJ, USA, 1991.

47. Burrough, P.A. Principles of Geographical Information Systems for Land Resources Assessment; Clarendon Press: Oxford, UK, 1986.

48. McConnan, I. Humanitarian Charter and Minimum Standards in Humanitarian Response; The Sphere Project: Geneva, Switzerland, 2011; p. 402.

49. Centro Nacional de Prevención de Desastres (CENAPRED). Activación de refugios temporales y atención a damnificados; CENAPRED: Ciudad de México, Mexico, 2009.

50. Kongsomsaksakul, S.; Chen, A.; Yang, C. Shelter location-allocation model for flood evacuation planning. J. Eastern Asia Soc. Transp. Stud. 2005, 6, 4237-4252.

51. Alam, J.B. Concept of flood shelter and its planning to cope with flood, Village Infrastructure to Cope with the Environment, Dhaka and Exeter, November 2000; Seraj, S.M., Hodgson, R.L., Ahmed, K.I., Eds.; Bangladesh University of Engineering and Technology and The Housing and Hazard Group: Dhaka, Bengal; Exeter, UK.

52. Xu, W.; Okada, N.; Takeuchi, Y.; Kajitani, Y. A diagnosis model for disaster shelter planning from the viewpoint of local people: Case study of nagata ward in kobe city, hyogo prefecture, Japan. Annu. Disaster Prev. Res. Inst. 2007, 1, 233-239.

53. Secretaría de Salud (SSA). Prácticas de higiene y sanidad para el proceso de alimentos, bebidas no alcohólicas y alcohólicas. NOM-120-SSA1-1994; Health_Ministry: Mexico City, Mecico, 1994. 
54. Simav, Ö.; Şeker, D.Z.; Gazioğlu, C. Coastal inundation due to sea level rise and extreme sea state and its potential impacts: Çukurova delta case. Turk. J. Earth Sci. 2013, 22, 671-680.

55. Isma'il, M.; Opeluwa Saanyol, I. Application of Remote Sensing (RS) and Geographic Information Systems (GIS) in flood vulnerability mapping: Case study of River Kaduna. Int. J. Geomat. Geosci. 2013, 3, 618-627.

56. Bhatt, C.M.; Srinivasa Rao, G.; Begum, A.; Manjusree, P.; Sharma, S.V.S.P.; Prasanna, L.; Bhanumurthy, V. Satellite images for extraction of flood disaster footprints and assessing the disaster impact: Brahmaputra floods of June-July 2012, Assam, India. Curr. Sci. 2013, 104, 1692-1700.

57. Theiling, C.H.; Burant, J.T. Flood inundation mapping for integrated floodplain management: Upper Mississippi river system. River Res. Appl. 2013, 29, 961-978. [CrossRef]

58. Qi, H.; Qi, P.; Altinakar, M.S. GIS-based spatial monte carlo analysis for integrated flood management with two dimensional flood simulation. Water Resour. Manag. 2013, 27, 3631-3645. [CrossRef]

59. Rawat, P.K.; Pant, C.C.; Tiwari, P.C.; Pant, P.D.; Sharma, A.K. Spatial variability assessment of river-line floods and flash floods in himalaya a case study using GIS. Disaster Prev. Manag. 2012, 21, 135-159. [CrossRef]

60. Paiva, R.C.D.; Collischonn, W.; Tucci, C.E.M. Large scale hydrologic and hydrodynamic modeling using limited data and a GIS based approach. J. Hydrol. 2011, 406, 170-181. [CrossRef]

61. Waisurasingha, C.; Aniya, M.; Hirano, A.; Sang-Arun, J.; Sommut, W. Application of remote sensing and gis for improving rice production in flood-prone areas: A case study in lower chi-river basin, Thailand. Jpn. Agric. Res. Q. 2008, 42, 193-201. [CrossRef]

62. Dutta, D.; Alam, J.; Umeda, K.; Hayashi, M.; Hironaka, S. A two-dimensional hydrodynamic model for flood inundation simulation: A case study in the lower mekong river basin. Hydrol. Process. 2007, 21, 1223-1237. [CrossRef]

63. Overton, I.C. Modelling floodplain inundation on a regulated river: Integrating GIS, remote sensing and hydrological models. River Res. Appl. 2005, 21, 991-1001. [CrossRef]

64. Chang, T.-J.; Hsu, M.-H.; Teng, W.-H.; Huang, C.-J. A GIS-assisted distributed watershed model for simulating flooding and inundation1. J. Am. Water Resour. Assoc. 2000, 36, 975-988. [CrossRef]

65. Warshall, S. A theorem on boolean matrices. J. ACM 1962, 9, 11-12. [CrossRef]

66. Floyd, R.W. Algorithm 97: Shortest path. Commun. ACM 1962, 5. [CrossRef]

67. Aini, A.; Salehipour, A. Speeding up the floyd-warshall algorithm for the cycled shortest path problem. Appl. Math. Lett. 2012, 25, 1-5. [CrossRef]

68. Höfner, P.; Möller, B. Dijkstra, floyd and warshall meet kleene. Form. Asp. Comput. 2012, 24, 459-476. [CrossRef]

69. Instituto Mexicano de Tecnología del Agua (IMTA). Informe de las Inundaciones de 2007 en Tabasco. Diagnóstico Preeliminar; Hidráulicos, C.D.A., Ed.; IMTA: México City, México, 2008; p. 16.

70. Instituto de Seguridad Social del Estado de Tabasco (ISSET). Information Request \#06400914; Instituto de Seguridad Social del Estado de Tabasco: Tabasco, Mexico, 2014; p. 2.

71. Secretaría de Gobernación (SEGOB). Information Request \#06645414; Secretaría de Gobernación: Tabasco, Mexico, 2014.

72. No Rest for Flood-Ravaged Mexico as New Storm Hits. Available onlline: https://www.rnw.org/archive/ no-rest-flood-ravaged-mexico-new-storm-hits (accessed on 30 December 2015).

73. Secretaría de Salud (SSA). Information Request \#00430314; Secretaría de Salud de Tabasco: Tabasco, México, 2014.

74. Secretaría de la Defensa Nacional. Information Request \#0000700097414; Secretaría de la Defensa Nacional (SEDENA): Mexico city, Mexico, 2014.

75. Protección Civil de Veracruz. Information Request \#0043114; Protección Civil de Veracruz (CPV): Veracruz, México, 2010.

76. Diagnóstico. Tipos de tráfico. Available online: http://caaarem.mx/Bases/Noticias07_09.nsf/b87c734d69 cddd80862573da005c3979/4a871e86bd66c1e78625760200821155/\$FILE/Capitulo\%203.pdf (accessed on 30 December 2015).

77. Programme des Nations Unies pour le développement (PNUD). Agua y Desarrollo. Agenda Municipal Para la Igualdad de Género; PNUD: México, Mexico, 2011; p. 92.

78. Prontuario de información geográfica municipal de los Estados Unidos Mexicanos. Available onlline: http://www3.inegi.org.mx/sistemas/mexicocifras/datos-geograficos/30/30193.pdf (accessed on 30 December 2015). 
79. INEGI Scince versión 05/2012. Available onlline: http://www.inegi.org.mx/est/scince/scince2010.aspx (accessed on 30 December 2015).

80. United States Geological Survey (USGS). Hydrosheds. Available online: http://gisdata.usgs.gov/website/ HydroSHEDS (accessed on 10 April 2011).

81. Stewart, S. Hurricane Karl Tropical Cyclone Report; National Hurricane Center: Miami, FL, USA, 2011; p. 17.

82. Instituto Nacional de Estadística y Geografía (INEGI). Modelos Digitales de Elevación. Available online: http://www.inegi.org.mx/geo/contenidos/datosrelieve/continental/queesmde.aspx (accessed on 19 May 2015).

83. Secretaría de Gobernación (SEGOB). Information Request \#0000400233914; Secretaría de Gobernación: Mexico City, Mexico, 2014.

84. Secretaría de Salud de Veracruz (SSV). Information Request \#00430314; Secretaría de Salud de Veracruz: Veracruz, Mexico, 2014.

85. Protección Civil del Estado de Veracruz. Information Request \#00430114; Protección Civil del Estado de Veracruz: Veracruz, Mexico, 2014; p. 2.

86. Secretaría de la Defensa Nacional (SEDENA). Information Request \#0000700097714; Secretaría de la Defensa Nacional: Mexico City, Mexico, 2014.

87. Diconsa. Information Request \#20150000010114; Diconsa: Mexico city, Mexico, 2014.

88. Protección Civil del Estado de Veracruz (PCV). Information Request \#00431314; PCV: Veracruz, Mexico, 2014.

89. Secretaría de la Defensa Nacional (SEDENA). Appendix of the Interview; Optva, S., Ed.; SEDENA: México, Mexico, 2010; p. 4.

90. Google Earth. Available online: https://www.google.com/earth/ (accessed on 30 December 2015).

91. Secretaría de Marina (SEMAR). Villahermosa, Tabasco; Secretaría de Marina: Mexico city, Mexico, $2015 ;$ p. 16.

92. Comisión Económica para Latin America y el Caribe. Características e Impacto Socioeconómico de las Lluvias Extremas de 2008; CEPAL: Vitacura, Chile, 2011; p. 149.

93. Programme des Nations Unies pour le développement (PNUD). Inundaciones en Tabasco 2009, Institucionalización de la Prevención en Las Tareas de Recuperación; United Nations: Mexico City, Mexico, 2009.

94. Secretaría de Gobierno (SEGOB); Gobierno_del_Estado_de_Tabasco; Comisión Económica para Latin America y el Caribe (CEPAL); Centro Nacional para la Prevención de Desastres (CENAPRED). Tabasco: Características e impacto socioeconómico de las inundaciones provocadas a finales de octubre y a comienzos de noviembre de 2007 por el frente frío número 4; Comisión Económica para Latin America y el Caribe (CEPAL): Vitacura, Chile, 2008; p. 231.

95. International Federation of Red Cross and Red Crescent. Mexico: Floods. Dref bulletin No. Mdrmx002 Glide: Fl-2007-000200-mex; IFRCRCS: Mexico City, Mexico; 2; November; 2007.

96. Dirección de Protección Civil. del Estado de Tabasco (PCT). Information Request \#06401914; Dirección de Protección Civil. del Estado de Tabasco: Tabasco, México, 2014.

97. Secretaría de la Defensa Nacional (SEDENA). Information Request \#0000700144114; Secretaría de la Defensa Nacional: Mexico City, México, 2014.

98. NASA. Flooding in southern mexico. Available online: http:/ /earthobservatory.nasa.gov/NaturalHazards / view.php?id=45900 (accessed on 17 December 2015).

99. Secretaría de Marina (SEMAR). Information Request \#0001300043214; Secretaría de Marina: Mexico City, Mexico, 2014.

100. Centro Nacional para la Prevención de Desastres (CENAPRED). Information Request \#0413000000214; Centro Nacional para la Prevención de Desastres: Mexico city, Mexico, 2014.

101. Hernández, J.; Santos, R.; Preciado, J.C.; Robles, V.; Rochin, R. Areas Inundadas en Villahermosa Tabasco Basado en el Modelo Digital de Elevación y la Presencia de Diques; National Institute of Public Health of Mexico: Cuernavaca, Mexico, 2007.

102. Santos-Reyes, J.; Alvarado-Corona, R.; Olmos-Peña, S. Learning from tabasco's floods by applying mort. Saf. Sci. 2010, 48, 1351-1360. [CrossRef]

103. Santos-Reyes, J.; Beard, A.N. Applying the sdms model to the analysis of the tabasco flood disaster in mexico. Hum. Ecol. Risk Assess. 2011, 17, 646-677. [CrossRef]

104. Feng, C.-C.; Wang, Y.-C. Giscience research challenges for emergency management in southeast asia. Nat. Hazards 2011, 59, 597-616. [CrossRef] 
105. Wang, Q.; Guo, H.; Chen, Y.; Lin, Q.; Li, H. Application of remote sensing for investigating mining geological hazards. Int. J. Digit. Earth 2013, 6, 449-468. [CrossRef]

106. Kaiser, R.; Spiegel, P.B.; Henderson, A.K.; Gerber, M.L. The application of geographic information systems and global positioning systems in humanitarian emergencies: Lessons learned, programme implications and future research. Disasters 2003, 27, 127-140. [CrossRef] [PubMed]

107. Lee, I.; Lee, K.; Torpelund-Bruin, C. Raster voronoi tessellation and its application to emergency modeling. Geo-spat. Inf. Sci. 2011, 14, 235-245.

(C) 2016 by the authors; licensee MDPI, Basel, Switzerland. This article is an open access article distributed under the terms and conditions of the Creative Commons by Attribution (CC-BY) license (http:/ / creativecommons.org/licenses/by/4.0/). 